\title{
Article \\ Development of Multi-Scale Carbon Nanofiber and Nanotube-Based Cementitious Composites for Reliable Sensing of Tensile Stresses
}

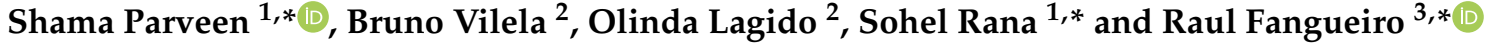 \\ 1 Department of Fashion and Textiles, School of Arts and Humanities, University of Huddersfield, \\ Huddersfield HD1 3DH, UK \\ 2 Department of Civil Engineering, University of Minho, Campus de Azurém, 4800-058 Guimarães, Portugal; \\ bmnvilela@gmail.com (B.V.); olinda.lagido@live.com.pt (O.L.) \\ 3 Department of Mechanical Engineering, University of Minho, Campus de Azurém, \\ 4800-058 Guimarães, Portugal \\ * Correspondence: parveenshama2011@gmail.com (S.P.); S.Rana@hud.ac.uk (S.R.); \\ rfangueiro@dem.uminho.pt (R.F.)
}

check for

updates

Citation: Parveen, S.; Vilela, B.;

Lagido, O.; Rana, S.; Fangueiro, R. Development of Multi-Scale Carbon Nanofiber and Nanotube-Based Cementitious Composites for Reliable Sensing of Tensile Stresses. Nanomaterials 2022, 12, 74. https:// doi.org/10.3390/nano12010074

Academic Editor:

Konstantinos Spyrou

Received: 16 November 2021

Accepted: 21 December 2021

Published: 28 December 2021

Publisher's Note: MDPI stays neutral with regard to jurisdictional claims in published maps and institutional affiliations.

Copyright: (c) 2021 by the authors. Licensee MDPI, Basel, Switzerland. This article is an open access article distributed under the terms and conditions of the Creative Commons Attribution (CC BY) license (https:// creativecommons.org/licenses/by/ $4.0 /)$.

\begin{abstract}
In this work, multi-scale cementitious composites containing short carbon fibers (CFs) and carbon nanofibers (CNFs) / multi-walled carbon nanotubes (MWCNTs) were studied for their tensile stress sensing properties. CF-based composites were prepared by mixing $0.25,0.5$ and $0.75 \mathrm{wt}$. $\%$ CFs (of cement) with water using magnetic stirring and Pluronic F-127 surfactant and adding the mixture to the cement paste. In multi-scale composites, CNFs/MWCNTs ( 0.1 and $0.15 \mathrm{wt}$.\% of cement) were dispersed in water using Pluronic F-127 and ultrasonication and CFs were then added before mixing with the cement paste. All composites showed a reversible change in the electrical resistivity with tensile loading; the electrical resistivity increased and decreased with the increase and decrease in the tensile load/stress, respectively. Although CF-based composites showed the highest stress sensitivity among all specimens at $0.25 \%$ CF content, the fractional change in resistivity (FCR) did not show a linear correlation with the tensile load/stress. On the contrary, multi-scale composites containing CNFs $(0.15 \%$ CNFs with $0.75 \%$ CFs) and MWCNTs (0.1\% MWCNTs with $0.5 \%$ CFs) showed good stress sensitivity, along with a linear correlation between FCR and tensile load/stress. Stress sensitivities of 6.36 and $11.82 \%$ /MPa were obtained for the best CNF and MWCNT-based multi-scale composite sensors, respectively.
\end{abstract}

Keywords: multi-scale composites; carbon fibers; cement; carbon nanotubes; stress sensing

\section{Introduction}

Cementitious composites are extensively used in civil infrastructures and are susceptible to deterioration of their properties over time. Therefore, health monitoring of cementbased buildings and infrastructures at periodic intervals is an important requirement to ensure the safety of the occupants, as well as to extend the lifespan of the infrastructures. The monitoring of real-time conditions and performance of structures, which is known as structural health monitoring (SHM), is performed mainly in the critical zones of the structures using various sensors [1,2]. The collected data are used to evaluate the health conditions of structures in order to take timely maintenance actions. SHM is frequently performed using various sensors such as optical fiber sensors, electrical resistance strain gauges, piezoelectric (PZT) ceramics, etc., each one of which has their own limitations [1,2] and, consequently, a great deal of research is currently underway to find an affordable, reliable and easy-to-use technique for SHM of civil infrastructures.

From past few years, investigations on the piezoresistive cementitious composites (i.e., composites which show change in their electrical resistivity with mechanical stress/strain) for SHM applications have accelerated considerably [1-3]. Piezoresistive cementitious 
sensors have better compatibility with civil structures and are durable [1-3]. These sensors were initially developed using short carbon fibers (SCFs) [4,5]. However, researchers are currently utilizing various electrically conductive nanofillers to introduce piezoresistivity into cementitious composites [6-8]. Nanomaterials are preferred over carbon fibers (CFs), as they are required at much lower concentrations and provide a positive influence on other properties of cementitious composites (e.g., mechanical properties, microstructure, thermal properties, etc.) due to their high surface area and aspect (i.e., length/diameter) ratio [9-11]. Extensive studies have been carried out to date on developing piezoresistive cementitious composites using different nanomaterials such as multi-wall carbon nanotubes (MWCNTs), graphene, nano graphite platelets, spiky spherical nickel powders containing nano tip, carbon nano fibers (CNF), nano carbon black (NCB), etc. [6,12,13].

Formation of a percolating electrical network is required to achieve piezoresistive properties in cementitious composites. Percolation threshold is defined as the critical concentration of conductive fillers to enable non-conductive cementitious matrices to show conductivity [7]. The percolation threshold of CFs ( $5 \mathrm{~mm}$ long and $10 \mu \mathrm{m}$ diameter) within a cementitious matrix was found to be between 0.5 ( 0.3 wt.\%) and 1 vol.\% ( 0.58 wt.\%) [4,5]. The percolation threshold of MWCNT in cementitious composites was also found in the similar range (between 0.3 and $0.6 \mathrm{wt}$.\% of cement) [14]. However, according to Yoo et al., the optimum concentration of MCNTs to introduce piezoresistivity into cementitious matrices was found to be 1 wt.\% (with respect to cement) $[7,8]$. For graphene-based cementitious composites, the percolation threshold was found to be between 1 and $5 \mathrm{wt}$ \% of graphene and the resulting composites showed good piezoresistive properties [12]. However, MWCNTs were considered as superior and more effective nanofillers for the fabrication of piezoresistive cementitious composites when compared to graphite nanofibers and graphene when used in similar concentrations [8]. More recently, the use of hybrid conductive fillers, i.e., the combination of two different fillers proved more effective in achieving superior conductivity and sensing properties in cementitious materials (these composites are known as multi-scale composites, as they are developed using hybrid reinforcements with micro- and nano-scale diameters [9]). For example, the use of CFs (15 mm in length and 5-7 $\mu \mathrm{m}$ in diameter) in combination with MWCNTs improved the stability of electrical resistivity of cementitious composites [14]. Reliable sensing of compressive loads and strains of cementitious composites was also achieved with hybrid conductive fillers composed of CFs and MWCNTs [15]. Cementitious composites containing these hybrid fillers demonstrated superior repeatability of sensing results when compared to CF-based cementitious composites [14]. Zhang et al. recently reported that a hybrid filler system containing CNT/NCB (40:60) showed a percolation threshold of 0.39 to 1.49 vol.\% (of mortar) and the resulting cementitious composites demonstrated a stable and sensitive piezoresistive property [16]. The observed percolation threshold and piezoresistivity of CNTs (and other nanomaterials), CFs and hybrid fillers in cementitious composites were different in different studies and this was attributed to the use of different types of nanomaterials and CFs (possessing different diameters and aspect ratios), their dispersion states, as well as different cement/water ratios and compositions used for the development of cementitious composites. Besides piezoresistivity, the hybrid filles were also found to be effective in improving the physical and mechanical properties of cementitious composites. For example, the use of $0.25 \mathrm{wt}$. $\%$ SCFs (of cement) with $0.75 \mathrm{wt}$ \% of MWCNTs (of cement) improved the flexural strength by $\sim 243 \%$, flexural modulus by $200 \%$ and toughness by $672 \%$ of plain cement-based composites [17]. Also, cementitious composites with 2.25 wt. $\%$ SCF and 0.5 wt.\% MWCNTs improved the tensile strength of plain cement composites by $\sim 53 \%$, tensile modulus by $60 \%$ and failure strain by $44 \%$ [18].

Due to the growing interest and prospect of piezoresistive cementitious composites in the civil engineering sector, a cost-effective and an easy fabrication method to develop these composites is highly desirable. Although cementitious composites containing hybrid fillers showed superior results, only a few studies have been carried out to date. Also, to the best of the authors' knowledge, the existing studies investigated the sensing properties 
of hybrid cementitious composites under compression loading and no study has been conducted to date under tensile loading mode. The present study, therefore, investigated and compared the piezoresistive properties of CF-reinforced, CF-MWCNT and CF-CNF hybrid filler-reinforced cementitious composites under tensile loading. CNFs and MWCNTs were selected as the conductive filles for developing these hybrid cementitious composites due to their high electrical conductivity (possessing electrical resistivity as low as $1 \times 10^{-4}$ and $2 \times 10^{-3}-1 \times 10^{-4} \Omega \mathrm{cm}$, respectively), relatively low cost when compared to other conductive nanomaterials such as single-walled CNTs, graphene, etc., high aspect ratio (250-2000 and 100-10,000, respectively), as well as their high mechanical properties (tensile strength of 2.92 and $10-60 \mathrm{GPa}$, respectively and tensile modulus of 240 and $1000 \mathrm{GPa}$, respectively] [19]. The comparison of the piezoresistive behavior of CF-MWCNT and CF-CNF hybrid filler-reinforced cementitious composites has also not been addressed in the existing literature. Moreover, a non-ionic surfactant, Pluronic F-127, was used for the first time to ensure proper dispersion of the fillers in the developed sensing cementitious composites. The piezoresistive properties of the composites were studied under cyclic tensile loading at different loading conditions. The fractional change in resistivity (FCR), its correlation with the applied load and stress sensitivity were determined and discussed in detail.

\section{Materials and Methods}

\subsection{Raw Materials}

Cementitious composite specimens were fabricated using the Portland cement CEM I $42.5 \mathrm{R}$ (purchased by Lisbon, Secil, Portugal). The properties of this cement are summarized in Table 1. Short CFs (Tenax ${ }^{\circledR}$, diameter: $7.0 \mu \mathrm{m}$, Length: $5 \mathrm{~mm}$ ) were supplied by Teijin Carbon Europe GmbH (Wuppertal, Germany) and MWCNTs and CNFs were supplied by Nanostructured \& Amorphous Materials, Inc. (Houston, TX, USA). Their physical and mechanical properties are summarized in Table 2. CNFs had an electrical conductivity of more than $100 \mathrm{~S} / \mathrm{cm}$. CNFs may contain significant amount of amorphous carbon, as well as residual catalysts and other inorganic impurities such as $\mathrm{Fe}, \mathrm{Co}, \mathrm{S}$, etc. and a trace amount of $\mathrm{Mg}, \mathrm{Cl}, \mathrm{Ca}, \mathrm{Cr}$, etc. [20] and these residual catalyst particles and other impurities can significantly influence the electrical conductivity of CNFs. Pluronic F-127 (the chemical structure is provided in Figure 1a), a non-ionic surfactant, was used to disperse MWCNTs/CNFs and CFs in water and was purchased from Sigma Aldrich (Algés, Portugal). A defoamer, tri-butyl phosphate (the chemical structure is provided in Figure 1b), was supplied by Acros Organics (Thermo Fischer Scientific, Porto Salvo, Portugal).

Table 1. Composition and properties of cement used in the present study.

\begin{tabular}{|c|c|c|}
\hline & Composition & $\begin{array}{l}\text { 95-100\% Clinker }+0-5 \% \text { Minor } \\
\text { Additional Components }\end{array}$ \\
\hline \multirow{8}{*}{$\begin{array}{l}\text { Ordinary Portland Cement } \\
\text { (CEM I 42.5 R) }\end{array}$} & Loss on ignition & $\leq 5 \%$ \\
\hline & Insoluble residue & $\leq 5 \%$ \\
\hline & Sulphur trioxide $\left(\mathrm{SO}_{3}\right)$ & $\leq 4.0 \%$ \\
\hline & Chloride $\left(\mathrm{Cl}^{-}\right)$ & $\leq 0.1 \%$ \\
\hline & Initial setting time & $\geq 60 \mathrm{~min}$ \\
\hline & Soundness & $\leq 10 \mathrm{~mm}$ \\
\hline & 2 days compressive strength & $\geq 20.0 \mathrm{MPa}$ \\
\hline & 28 days compressive strength & $\geq 42.5 \overline{\mathrm{MPa}} \leq 62.5 \mathrm{MPa}$ \\
\hline
\end{tabular}

${ }^{1}$ Source:www.secil.pt, accessed on 12 January 2013, Lisbon, Portugal 
Table 2. Properties of carbon fibers, CNFs, MWCNTs, Pluronic F-127 and defoamer.

\begin{tabular}{|c|c|c|c|c|c|}
\hline Materials & \multicolumn{5}{|c|}{ Physical and Mechanical Properties } \\
\hline \multirow{5}{*}{$\begin{array}{l}\text { Tenax-e HTA } 40 \\
\text { E13 6k } 400 \text { tex }\end{array}$} & $\begin{array}{c}\text { Tensile } \\
\text { Strength }(\mathrm{MPa})\end{array}$ & $\begin{array}{c}\text { Tensile } \\
\text { Modulus (GPa) }\end{array}$ & $\begin{array}{c}\text { Elongation at } \\
\text { Break (\%) }\end{array}$ & $\begin{array}{c}\text { Filament } \\
\text { Diameter }(\mu \mathrm{m})\end{array}$ & $\operatorname{Density}\left(\mathrm{g} / \mathrm{cm}^{3}\right)$ \\
\hline & 4100 & 240 & 1.7 & 7 & 1.77 \\
\hline & \multicolumn{5}{|c|}{ Physical Properties } \\
\hline & \multicolumn{2}{|c|}{ Diameter (nm) } & \multirow{2}{*}{ Length $(\mu \mathrm{m})$} & \multirow{2}{*}{$\begin{array}{c}\text { Surface Area } \\
\left(\mathrm{m}^{2} / \mathrm{g}\right)\end{array}$} & \multirow{2}{*}{ Purity (\%) } \\
\hline & Inside & Outside & & & \\
\hline $\mathrm{MWCNT}^{1}$ & $2-5$ & $<8$ & $10-30$ & $350-420$ & $>95 \%$ \\
\hline CNF & & $200-600 \mathrm{~nm}$ & $5-50 \mu \mathrm{m}$ & $>18$ & $\begin{array}{c}>70 \text { wt. } \%, \\
\text { Ash: <5 wt. } \%\end{array}$ \\
\hline Pluronic F-127 & Non-ioni & surfactant, molec & Ir weight: 12,50 & $/ \mathrm{mol}, \mathrm{CMC}: 95$ & $1000 \mathrm{ppm}$ \\
\hline
\end{tabular}

${ }^{1}$ Source: Nanostructured \& Amorphous Materials, Inc., Katy, TX, USA.

$$
\begin{gathered}
\mathrm{CH}_{3} \\
\mathrm{I} \\
\mathrm{OH}-\left[\mathrm{CH}_{2} \mathrm{CH}_{2} \mathrm{O}\right]_{100}-\left[\mathrm{CH}_{2} \mathrm{CHO}\right]_{65}-\left[\mathrm{CH}_{2} \mathrm{CH}_{2} \mathrm{O}\right]_{100}-\mathrm{H}
\end{gathered}
$$

poly(ethylene oxide). poly(propylene oxide). poly(ethylene oxide)

(a)

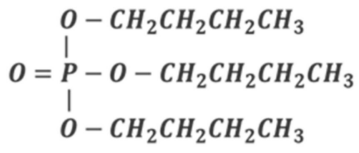

(b)

Figure 1. Chemical structure of (a) Pluronic F-127 and (b) Tri butyl Phosphate.

\subsection{Characterization of Morphology of Carbon Nanofibers and Nanotubes}

Scanning Electron Microscopy (FEG-SEM, NOVA 200 Nano SEM, FEI, Hillsboro, Oregon, USA) at an acceleration voltage of $10 \mathrm{kV}$ was used to study the morphology of MWCNTs and CNFs. To avoid the charging of samples during SEM, they were coated with a $30 \mathrm{~nm}$ film of Au-Pd in a high-resolution sputter coater (208HR Cressington, Watford, UK).

\subsection{Preparation of Aqueous Suspensions of Carbon Fibers, Carbon Nanofibers and Nanotubes}

The schematic diagram, showing the preparation of various aqueous suspensions, is shown in Figure 2. The aqueous suspensions of CF, using $5 \mathrm{wt}$.\% of Pluronic F-127 (on the weight of water), were prepared by first mixing Pluronic F-127 in water with the help of magnetic stirring for $10 \mathrm{~min}$. CFs were then added in the surfactant solution and mixed with the help of magnetic stirring for another $10 \mathrm{~min}$. In case of aqueous suspensions containing CFs, along with MWCNTs or CNFs, MWCNT or CNF powder was first added to the surfactant solution and then magnetic stirring was carried out for $10 \mathrm{~min}$ to ensure that there were no big lumps of MWCNTs/CNFs in the aqueous suspensions. The MWCNT/CNF surfactant suspensions were then kept in a bath ultrasonicator (Sonica Ultrasonicator 3200 S3, Milan, Italy) operated at $40 \mathrm{kHz}$ frequency and $180 \mathrm{~W}$ power for $1 \mathrm{~h}$. After removing the MWCNT/CNF suspensions from the ultrasonicator, CFs were added and mixed using magnetic stirring for $10 \mathrm{~min}$. The defoamer (in the weight ratio of 1:0.5 with respect to Pluronic F-127) was then added to the suspensions, which were used later for the fabrication of cementitious composites. For the characterization of CNT/CNF dispersion in aqueous suspensions, the defoamer and CFs were not added to avoid film formation by the defoamer and agglomeration caused by CFs during the characterization of aqueous suspensions. Figure 2 shows the magnetic stirring and ultrasonication processes of aqueous suspensions and Figure $3 \mathrm{c}$ shows a suspension containing MWCNTs and CFs. 


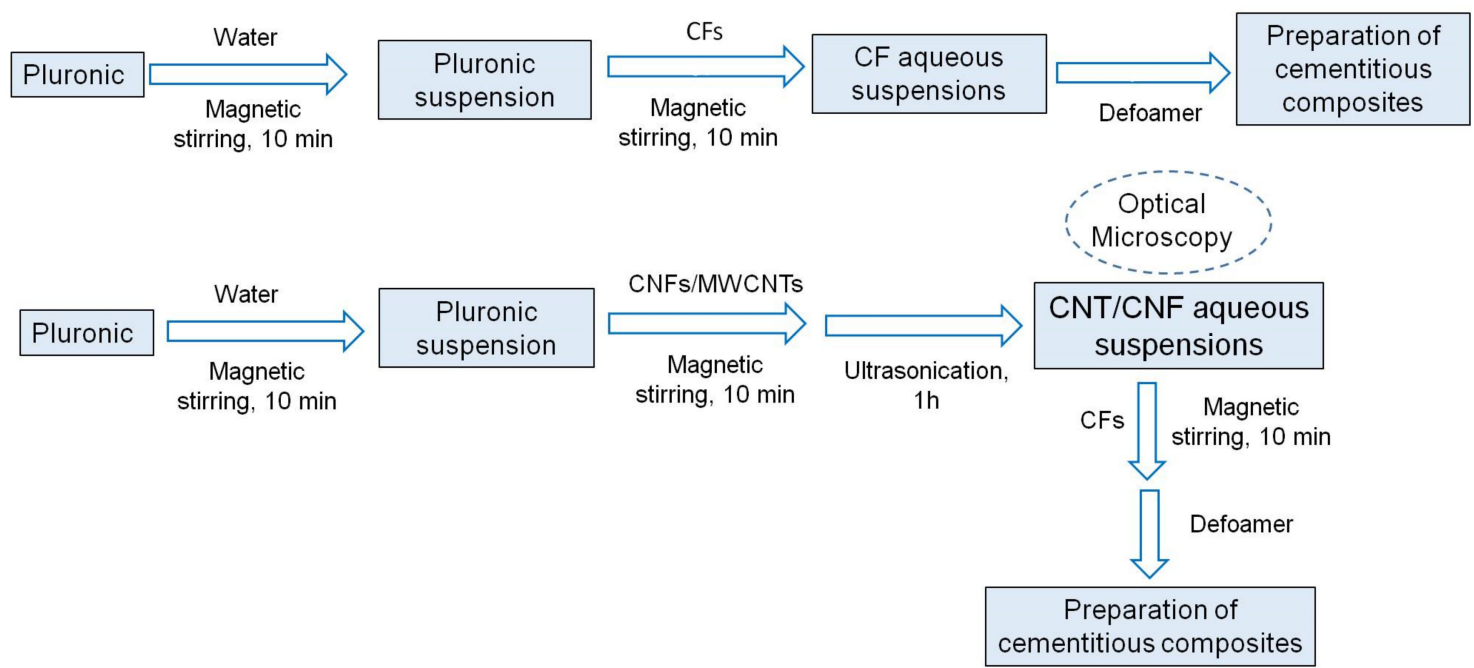

Figure 2. Schematic diagram showing the preparation of aqueous suspensions for fabrication of cementitious composites.

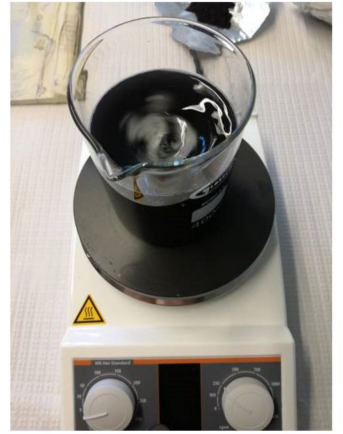

(a)

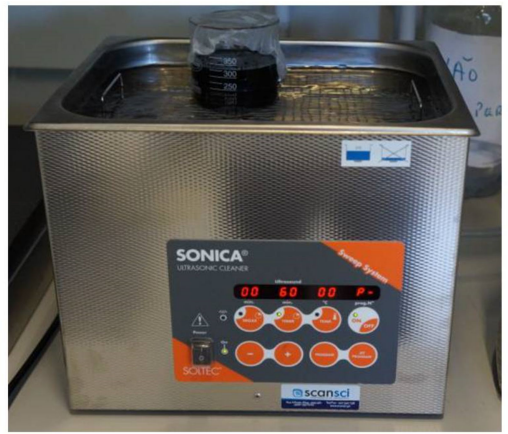

(b)

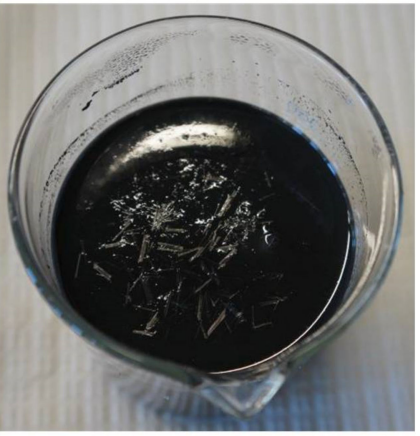

(c)

Figure 3. Preparation of aqueous suspensions: (a) magnetic stirring, (b) ultrasonication and (c) the aqueous suspension containing CFs and MWCNTs.

\subsection{Characterization of Aqueous Suspensions}

Optical microscopy (Olympus BH2 Microscope, Hamburg, Germany) was used to identify the CNT/CNF agglomerates in the aqueous suspensions. This characterization was performed to also study the homogeneity of the prepared suspensions. To carry out the optical microscopic analysis, a drop of MWCNT/CNFs (without CF) suspension was placed on a glass slide and covered with a cover slip. The images were captured in 5 different places of the drop. The analysis was repeated for 3 times and the images were captured in two different magnifications to clearly understand the quality of the prepared suspensions.

\subsection{Preparation of Cementitious Composites}

Cementitious composites were fabricated using aqueous suspensions of CF or CF with MWCNTs/CNFs (315 mL) and cement (900 g) following EN 196-1:2006 standard. A set of unreinforced samples, i.e., plain mortars, were also prepared using water $(315 \mathrm{~mL})$ to compare with the reinforced cementitious composites. The weighed amount of cement was mixed with the aqueous suspensions using a Hobart mixer; the mixer was set for $1.5 \mathrm{~min}$ at a slow speed $(140 \pm 5 \mathrm{rpm})$ and then $1.5 \mathrm{~min}$ at a high speed $(285 \pm 10 \mathrm{rpm})$. The mixtures were then poured into the molds (three samples were prepared for each mixture). The specimens were prepared in a dog-bone shaped mold (having a cross section of $30 \mathrm{~mm} \times 20 \mathrm{~mm}$, the distance between the inner grid for voltage measurement was $70 \mathrm{~mm}$ and the outer grid for passing current was $80 \mathrm{~mm}$ ), as shown in Figure 4, in order 
to perform the piezoresistive measurement. The grids were made of copper foils having $30 \mathrm{~mm} \times 15 \mathrm{~mm}$ dimension.

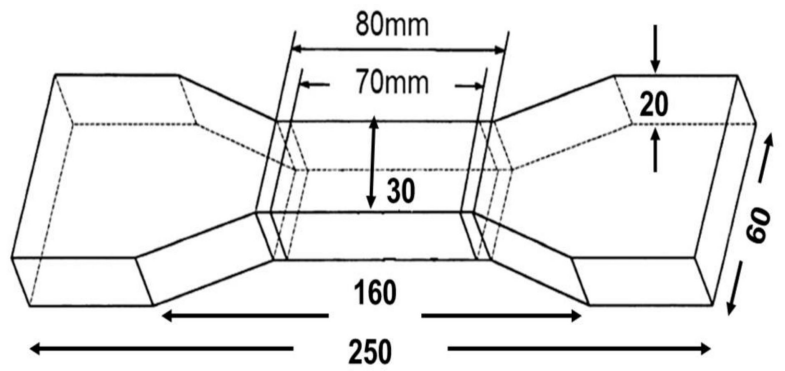

(a)

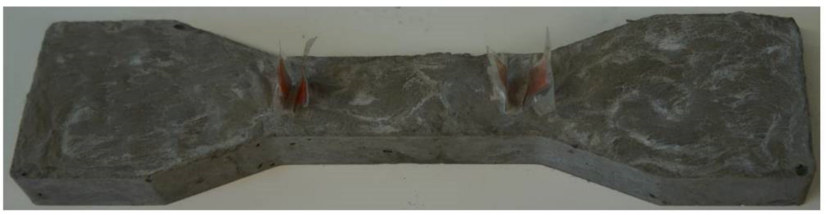

(b)

Figure 4. (a) Dimension of the dog bone samples. (b) Samples used for piezoresistive characterization.

The molds were placed on a jolting machine for $30 \mathrm{~s}$ to remove the entrapped air. The molded samples were then covered by cellophane and placed in a chamber with a moist atmosphere for $24 \mathrm{~h}$. The samples were demolded after $24 \mathrm{~h}$ and kept submerged in water for 28 days at $25{ }^{\circ} \mathrm{C}$. The samples were taken out $4 \mathrm{~h}$ before the test, wiped with a cotton cloth and kept at the room temperature prior to the piezoresistive characterization. The compositions of different samples prepared are listed in Table 3.

Table 3. Composition of different samples prepared for piezoresistive characterization (each sample contains $900 \mathrm{~g}$ of cement).

\begin{tabular}{cccc}
\hline Samples & CF (wt. \% of Cement) & $\begin{array}{c}\text { CNF (wt. \% of } \\
\text { Cement) }\end{array}$ & $\begin{array}{c}\text { MWCNT (wt. \% of } \\
\text { Cement) }\end{array}$ \\
\hline Plain Mortar & 0 & 0 & 0 \\
\hline 0.25 CF & 0.25 & 0 & 0 \\
\hline $0.5 \%$ CF & 0.50 & 0 & 0 \\
\hline $0.75 \%$ CF & 0.75 & 0 & 0 \\
\hline $0.25 \%$ CF 0.1\% CNF & 0.25 & 0.10 & 0 \\
\hline $0.5 \%$ CF 0.1\% CNF & 0.50 & 0.10 & 0 \\
\hline $0.75 \%$ CF 0.1\% CNF & 0.75 & 0.10 & 0 \\
\hline $0.25 \%$ CF 0.15\% CNF & 0.25 & 0.15 & 0 \\
\hline $0.5 \%$ CF 0.15\% CNF & 0.50 & 0.15 & 0.10 \\
\hline $0.75 \%$ CF0.15\% CNF & 0.75 & 0.15 & 0.10 \\
\hline $0.25 \%$ CF 0.1\% CNT & 0.25 & 0 & 0.10 \\
\hline $0.5 \%$ CF 0.1\% CNT & 0.50 & 0 & 0.15 \\
\hline $0.75 \%$ CF 0.1\% CNT & 0.75 & 0 & 0.15 \\
\hline $0.25 \%$ CF 0.15\% CNT & 0.25 & 0 & 0.15 \\
\hline $0.5 \%$ CF 0.15\% CNT & 0.50 & 0 & \\
\hline $0.75 \%$ CF 0.15\% CNT & 0.75 & 0 & 0 \\
\hline
\end{tabular}

\subsection{Characterization of Piezoresistive Properties}

The test setups for the characterization of the electrical resistance and stress sensing properties of cementitious composites are shown in Figure 5. Stress sensing properties were 
characterized by measuring the electrical resistivity of samples using a digital multimeter (Agilent 34460a, Santa Clara, CA, USA) in the elastic regime of tensile loading with three different loading rates: 20,30 and 40 N.s ${ }^{-1}$. For each loading rate, the load was increased from $0 \mathrm{~N}$ up to $10 \mathrm{~s}$ and then decreased to $0 \mathrm{~N}$ at the same unloading rate. 5 cycles of loading and unloading (20 s per cycle) were studied at each loading rate to verify the repeatable performance of the developed cementitious composites. The DC electrical resistance was measured simultaneously during the mechanical testing using a four-probe method. Fractional change in the resistivity (FCR) and stress sensitivity of the composites in each cycle were calculated using the following equations:

$$
\begin{gathered}
F C R=\frac{\text { final resistivity }(\rho)-\text { initial resistivity }\left(\rho_{0}\right)}{\text { initial resistivity }\left(\rho_{0}\right)} \\
\text { Stress Sensitivity }=\frac{100 \times \text { FCR }}{\text { Applied tensile stress }}
\end{gathered}
$$
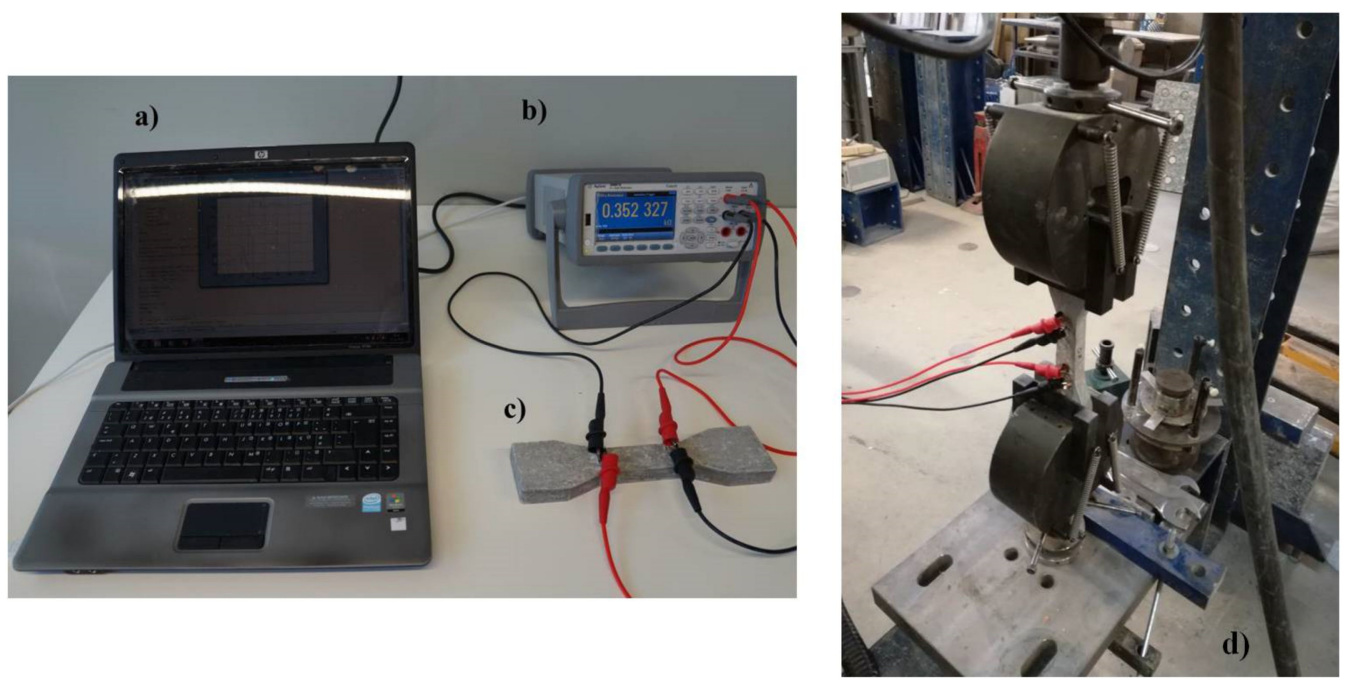

Figure 5. Measurement of (a) electrical resistance and $(\mathbf{b}, \mathbf{c})$ piezoresistive property of cementitious composites (d) piezoresistive property of cementitious composites in tensile mode.

\subsection{Microstructural Characterization of Developed Cementitious Composites}

The fractured surfaces of developed specimens were analyzed by using SEM (FEGSEM, NOVA 200 Nano SEM, FEI) using the secondary electron mode and an acceleration voltage of $10 \mathrm{kV}$ after coating with a thin film $(30 \mathrm{~nm})$ of Au-Pd in a high-resolution sputter coater (208HR Cressington, Watford, UK).

\section{Results}

\subsection{Morphology of Carbon Fibers, Nanofibers and Nanotubes}

The image of short CFs is shown in Figure 6a. The SEM micrographs of CNF and MWCNTs are shown in Figure 6b,c, respectively. Significant entanglements or agglomeration can be observed in the case of CNFs. However, MWCNTs showed the highest degree of agglomeration and clustering in the powder, as can be seen from Figure $6 \mathrm{c}$. Transmission electron microscope (TEM) images of MWCNT aqueous suspensions also showed clustering and entanglements of nanotubes, as shown in Figure $6 \mathrm{~d}$. Therefore, to break these MWCNT/CNF agglomerates and disperse them homogeneously within the cementitious matrix, a combination of magnetic stirring (10 min) and ultrasonication $(1 \mathrm{~h})$ was used. 


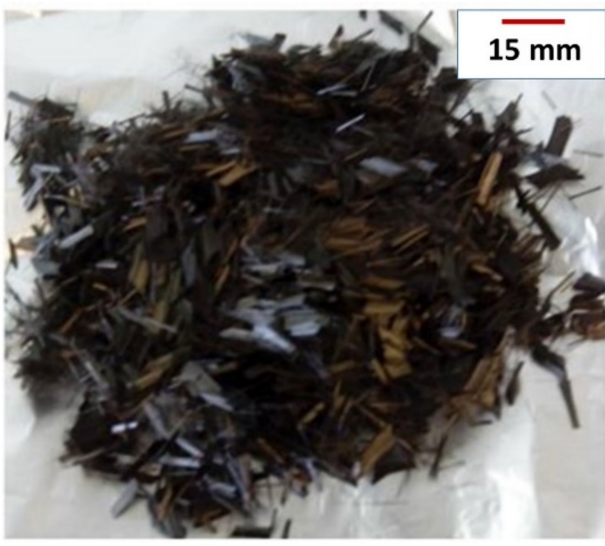

(a)

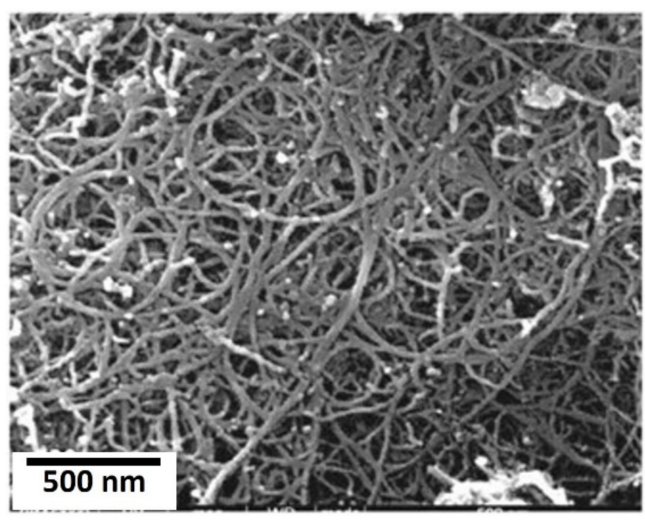

(c)

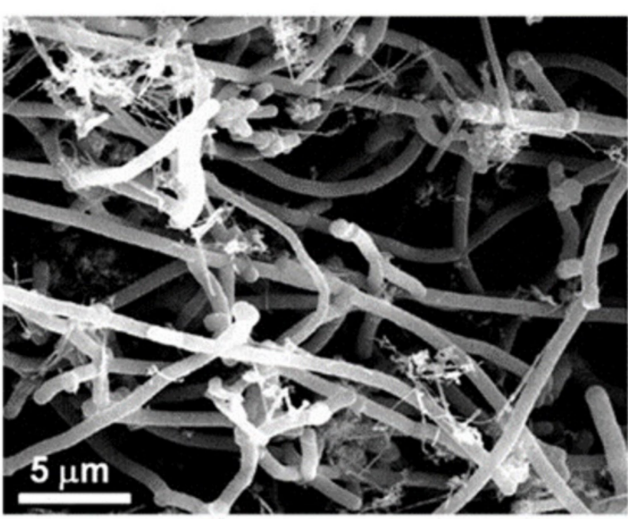

(b)

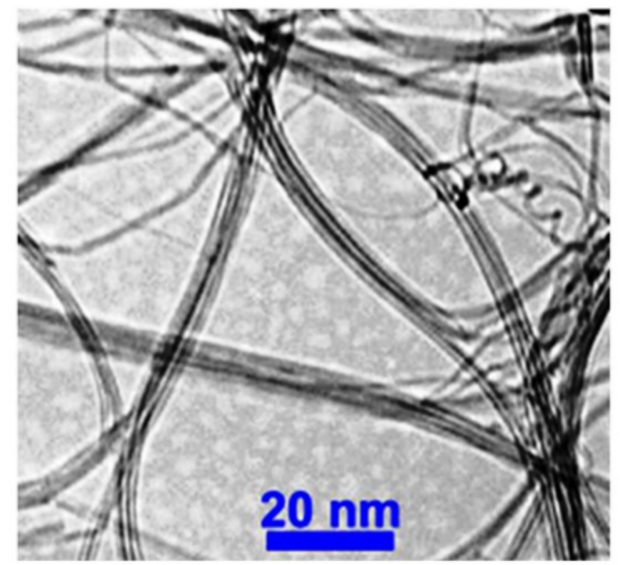

(d)

Figure 6. Reinforcement of cementitious composites: (a) short CFs, (b) SEM micrograph of CNFs and (c) SEM micrograph MWCNTs and (d) TEM image of MWCNTs, taken from manufacturer website.

\subsection{Aqueous Suspensions of MWCNT and CNT}

The optical micrographs of aqueous suspensions of MWCNT and CNF are shown in Figure 7. It is clear from Figure 7a that MWCNTs could be homogeneously dispersed in water using a Pluronic F-127-assisted ultrasonication process. MWCNTs were dispersed without any noticeable agglomeration. Homogeneous dispersion of CNTs and CNFs is prerequisite for developing high performance cementitious composites [9] and the use of Pluronic F-127 was proven to be effective in achieving homogenous CNT dispersion in previous studies also [10,11]. It can also be clearly observed from Figure 7c that dispersed MWCNTs formed electrically conductive pathways within the aqueous medium. The aqueous suspension of CNF also showed homogeneous dispersion free from noticeable CNF agglomerates. To the best of authors' knowledge, Pluronic F-127 has been utilized to disperse CNFs for the first time in the present study and a homogeneous dispersion was obtained due to the steric stabilization induced by Pluronic F-127 molecules, as previously reported for CNTs [10,11]. However, in this case, a few CNFs were seen to form bundles with each other and formed a greater number of noticeable electrically conductive pathways when compared to MWCNTs within the aqueous medium, as can be seen from Figure 7d. 


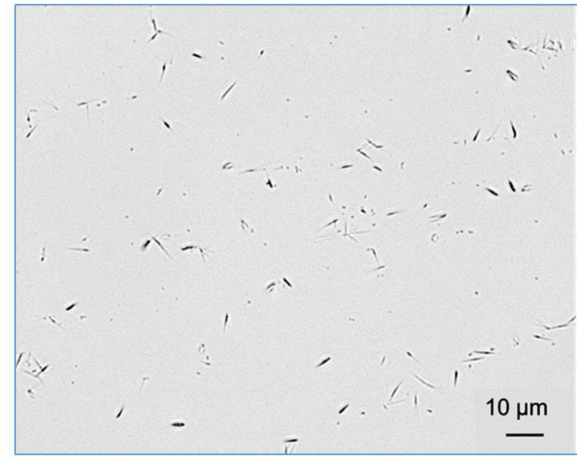

(a)

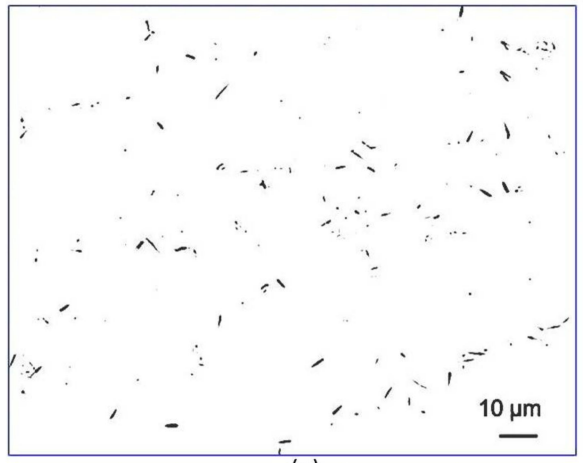

(c)

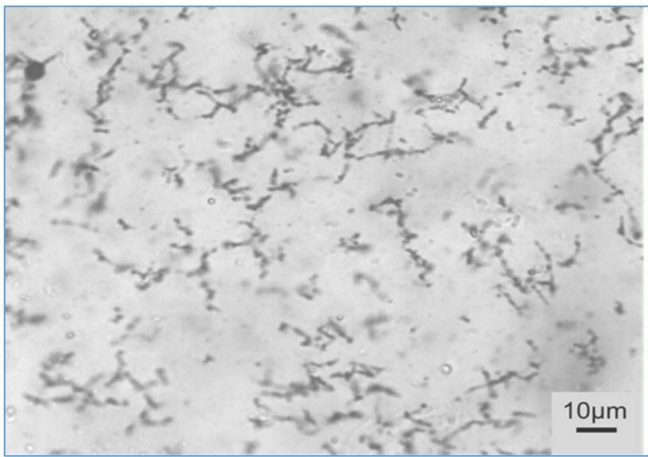

(b)

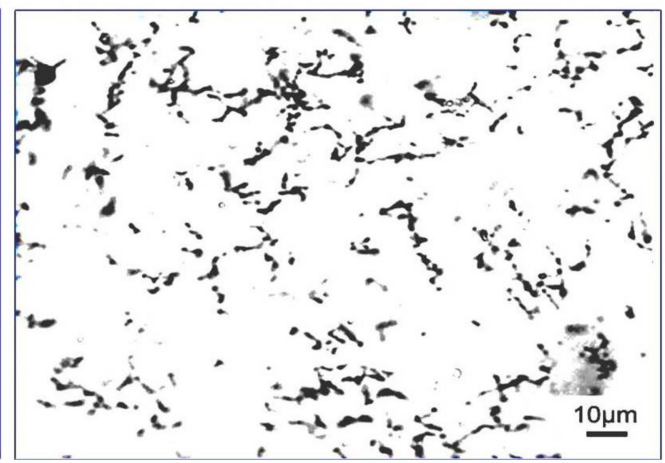

(d)

Figure 7. Optical Micrographs of the aqueous suspensions of (a) $0.2 \%$ MWCNT\% with 5 wt.\% Pluronic F-127, (b) $0.2 \%$ CNF with 5 wt.\% Pluronic F-127, (c,d) are the high contrast micrographs of $(\mathbf{a}, \mathbf{b})$, respectively, showing the conductive networks formed by CNFs and MWCNTs.

\subsection{Electrical Resistance of Cementitious Composites}

The electrical resistivity of mortar containing only $\mathrm{CF}$ and mortar containing $\mathrm{CF}$ and different concentrations of CNF and MWCNT is presented in Figure 8. It can be noticed that mortars containing $0.25 \mathrm{wt}$.\% CF had an electrical resistivity of $3.7 \Omega . \mathrm{m}$. The electrical resistivity decreased with the increase in the CF wt.\% and the sample containing 0.75 wt. $\%$ CF showed an electrical resistivity of $0.6 \Omega . \mathrm{m}$. The electrical resistivity obtained in this case was lower when compared to previously reported mortar samples containing $\mathrm{CF}$, carbon black and other nanomaterials [21-24].

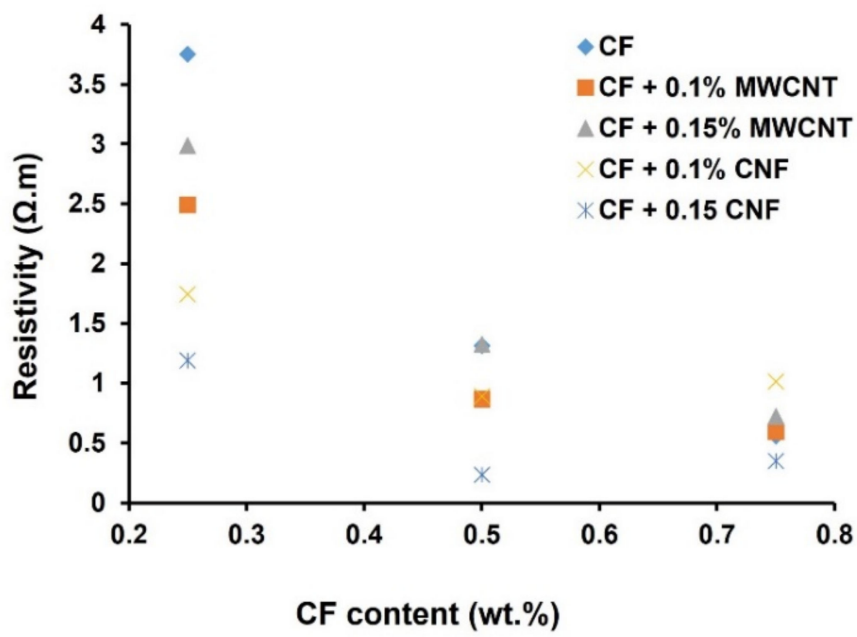

Figure 8. Influence of $\mathrm{CF}, \mathrm{CNF}$ and MWCNT on the electrical resistance of cementitious composites. 
The use of Pluronic F-127 in the present study was believed to improve the dispersion of CFs within the mortar paste, leading to the reduced clustering of CFs and resulting in a lower porosity of the reinforced cementitious composites. This significantly improved the electrical conductivity of cementitious composites. It is clear from Figure 8 that the addition of MWCNT and CNF significantly reduced the electrical resistivity of CF-reinforced cementitious composites. This was attributed to the fact that the highly conducting MWCNTs and CNFs can bridge the conducting paths formed by CFs and, hence, improved the conductivity of composites [15]. It can also be observed that composites with CNFs at 1.5 wt.\% showed a lower resistivity when compared to composites prepared with MWCNTs. This could be due to the better formation of conductive paths with CNFs due to their larger dimensions, as also observed in Figure 7d. Composites with MWCNTs, on the other hand, showed a higher resistivity at the higher concentration, i.e., $1.5 \mathrm{wt} \%$, probably due to formation of CNT agglomerates, which resulted in the increased porosity and higher resistivity of composites. This observation agrees with the previous studies on CNT-reinforced cementitious composites [25].

\subsection{Response of Cementitious Composites to Cyclic Tensile Loading}

3.4.1. Effect of Cyclic Tensile Loading on Electrical Resistivity

The electrical response of CF-reinforced cementitious composites containing $0.25,0.5$ and 0.75 wt.\% CF to cyclic tensile loading is shown in Figure 9. These responses were achieved at five loading-unloading cycles at three different loading rates: 20, 30 and $40 \mathrm{~N} / \mathrm{s}$. Each loading and unloading cycle took $10 \mathrm{~s}$ and therefore, the loading cycles reached 200, 300 and $400 \mathrm{~N}$, respectively, for these three loading rates and came back to $0 \mathrm{~N}$ after each unloading cycle. It can be clearly noticed that the electrical resistivity showed a reversible change with the tensile loading, i.e., the electrical resistivity increased with the increase in loading and decreased when the loading decreased in the unloading cycles. The increase in electrical resistivity of short CF-reinforced cementitious composites with increased tensile loading has been previously reported [4,5]. The extension of composites due to tensile loading caused a reduction in the electrical contact points between short CFs, leading to a reduction in the conductive pathways and an increase in the electrical resistivity of composites [4,5]. The change in resistivity in all three studied load levels (i.e., 200, 300 and $400 \mathrm{~N}$ ) was reversible, indicating that these load levels were within the elastic regime of the composites and did not introduce a permanent damage within the composite structure.

Composites containing different CF contents showed a similar behavior, except a flattening of electrical resistivity at the maximum load was noticed for the composites containing $0.25 \mathrm{wt}$ \% CF (Figure 9a1-a3). This delayed electrical response from the composites in the region when the loading cycle reversed was probably attributed to a relatively lesser number of electrical contacts between CFs in the case of $0.25 \mathrm{wt} \% \mathrm{CF}$. The electrical response of hybrid cementitious composites containing CF and different concentrations of CNF and MWCNT are shown in Figures 10-13. It can be noticed that these composites also showed similar trends of changing their electrical resistivity with tensile loading, i.e., the electrical resistivity increased and decreased reversibly with the increase and decrease in the tensile loading, respectively. However, the extent of electrical resistivity change in different cycles was dependent on the loading rates/maximum load as well as on the composition of the composites. 

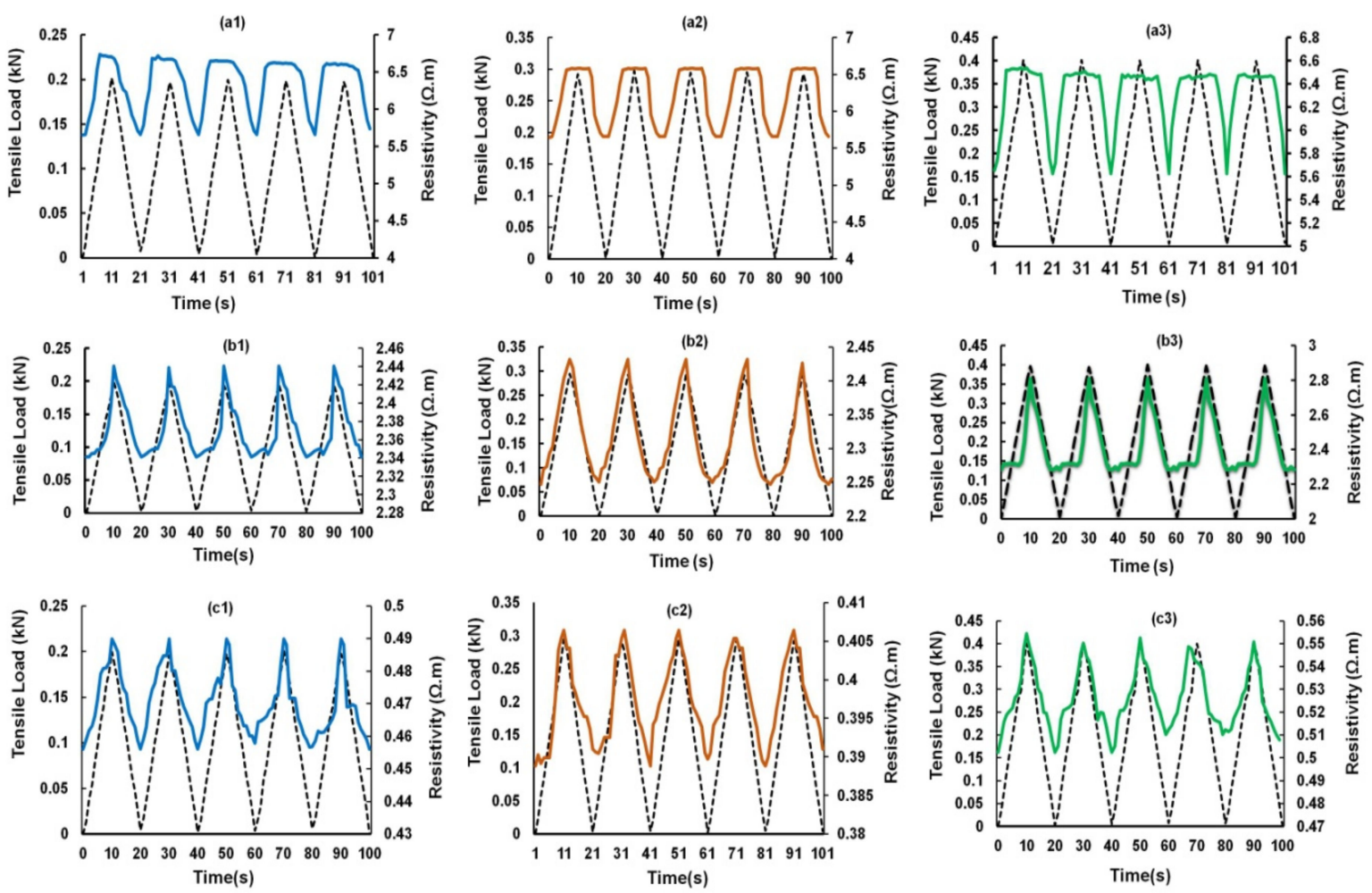

Figure 9. Change of electrical resistance with cyclic tensile load of CF reinforced cementitious composites at different peak loads containing $0.25 \%$ CF (a1-a3), $0.50 \%$ CF (b1-b3) and $0.75 \%$ CF (c1-c3).
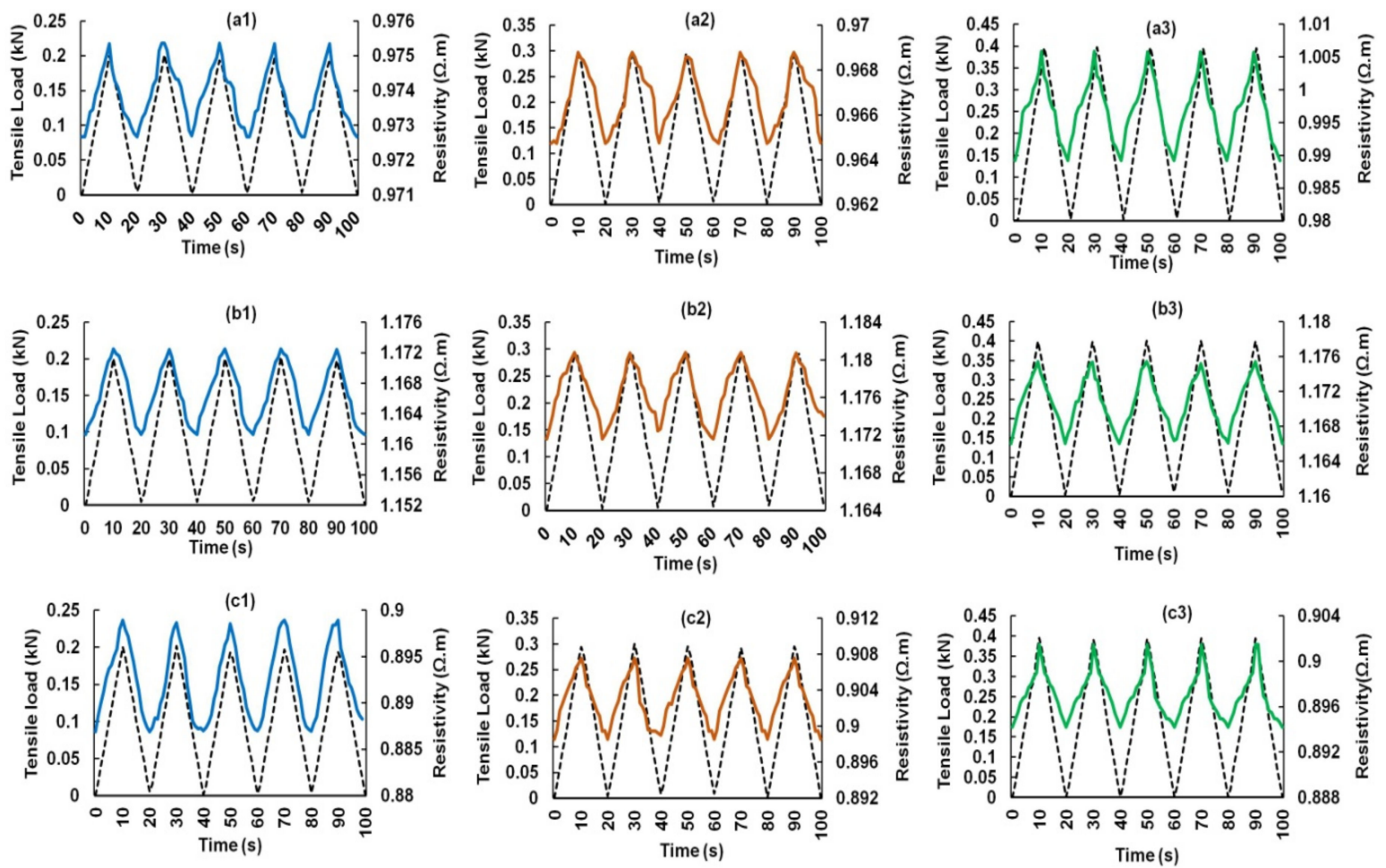

Figure 10. Change of electrical resistance with cyclic tensile load of $0.1 \%$ CNF-reinforced cementitious composites at different peak loads containing $0.25 \% \mathrm{CF}$ (a1-a3), $0.50 \% \mathrm{CF}$ (b1-b3) and $0.75 \% \mathrm{CF}$ (c1-c3). 

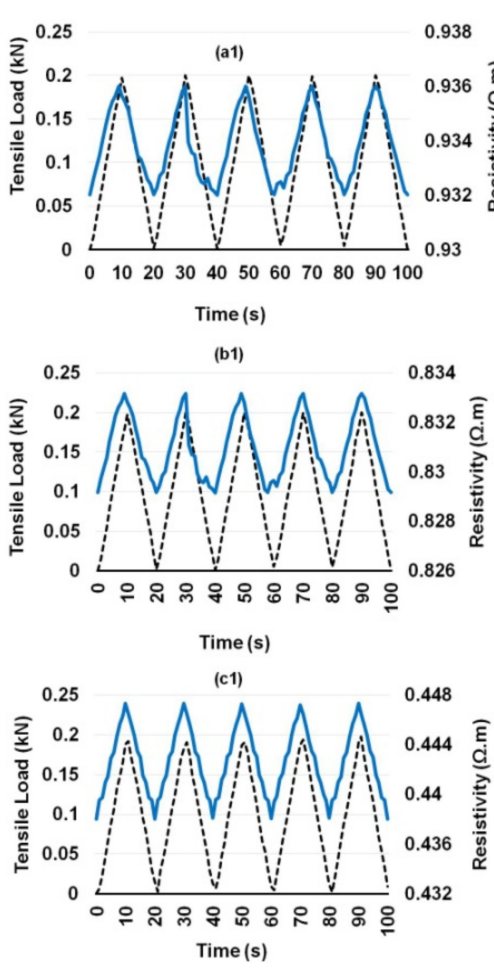

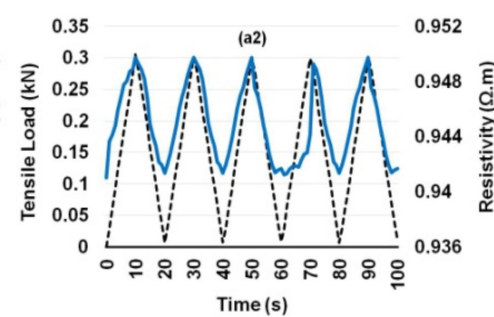

(b2)
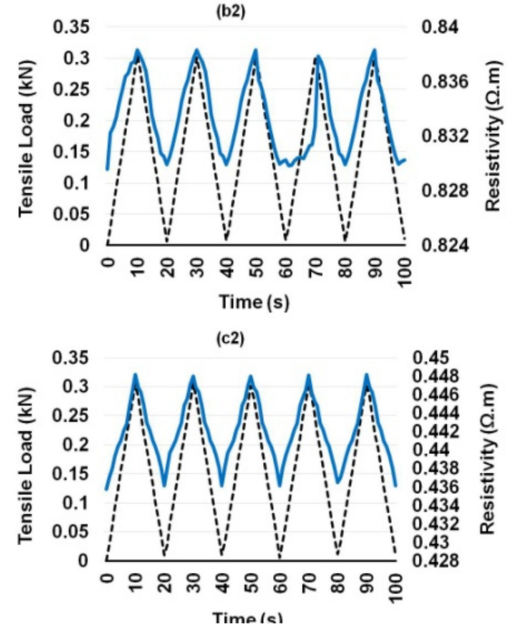

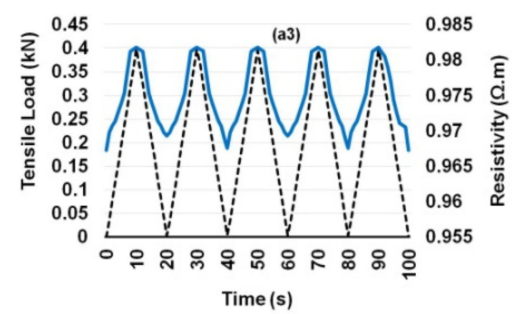

(b3)
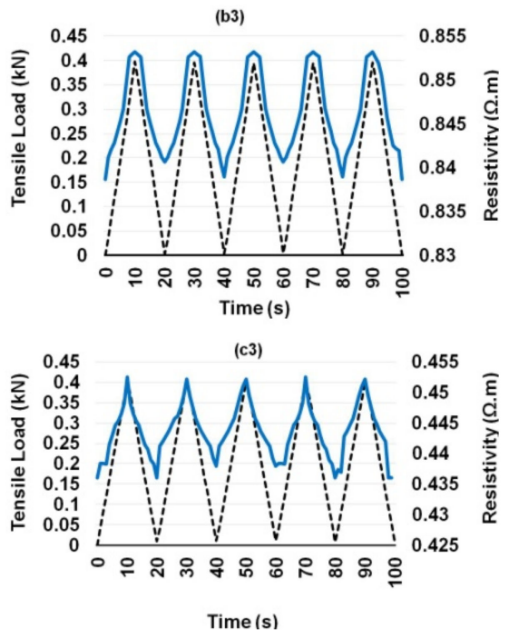

Figure 11. Change of electrical resistance with cyclic tensile load of $0.15 \%$ CNF-reinforced cementitious composites at different peak loads containing $0.25 \% \mathrm{CF}(\mathbf{a} 1-\mathbf{a} 3), 0.50 \% \mathrm{CF}(\mathbf{b} 1-\mathbf{b} 3)$ and $0.75 \%$ CF (c1-c3).
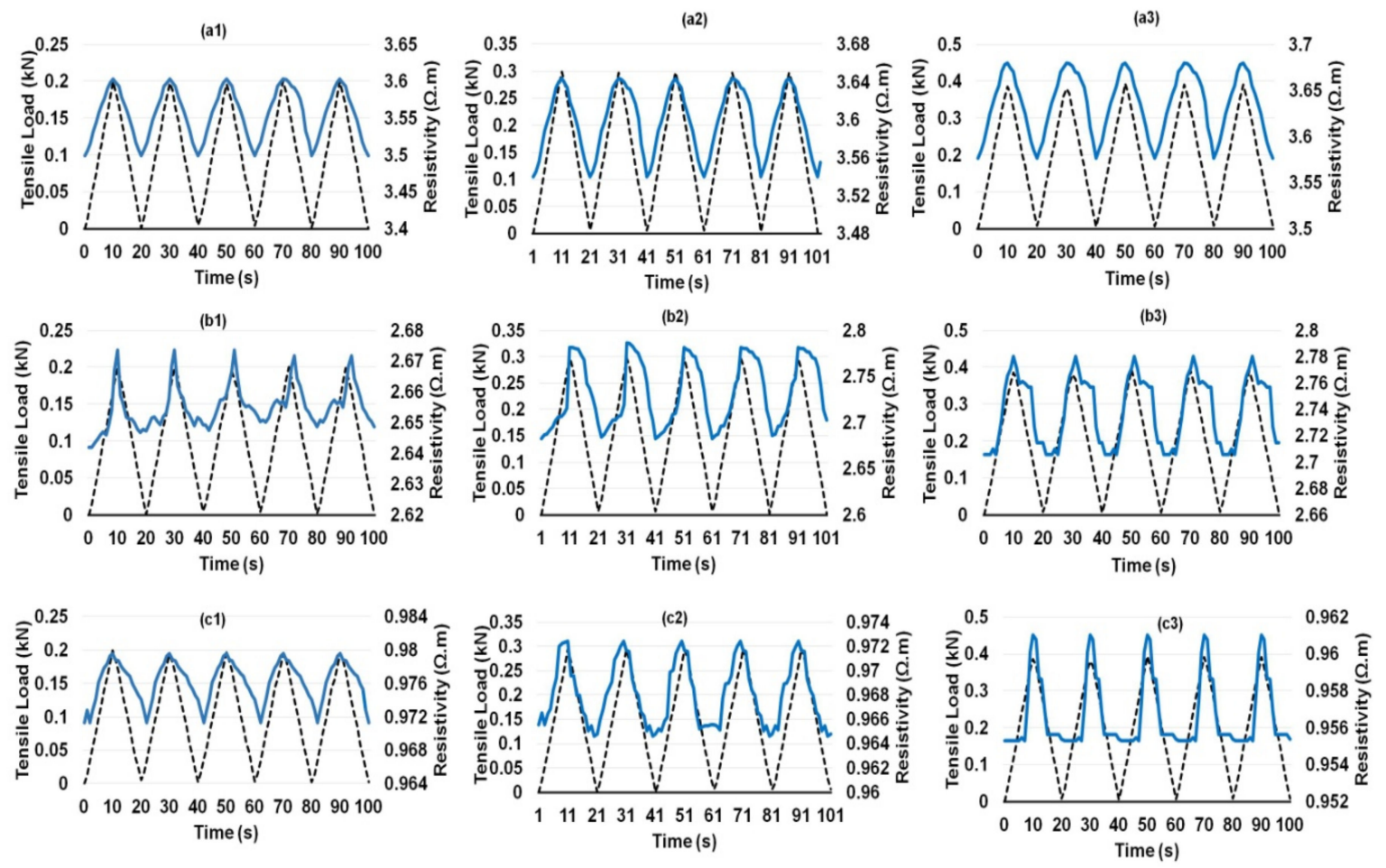

Figure 12. Change of electrical resistance with cyclic tensile load of $0.1 \%$ MWCNT-reinforced cementitious composites at different peak loads containing $0.25 \% \mathrm{CF}$ (a1-a3), 0.50\%SCF (b1-b3) and 0.75\% SCF (c1-c3). 

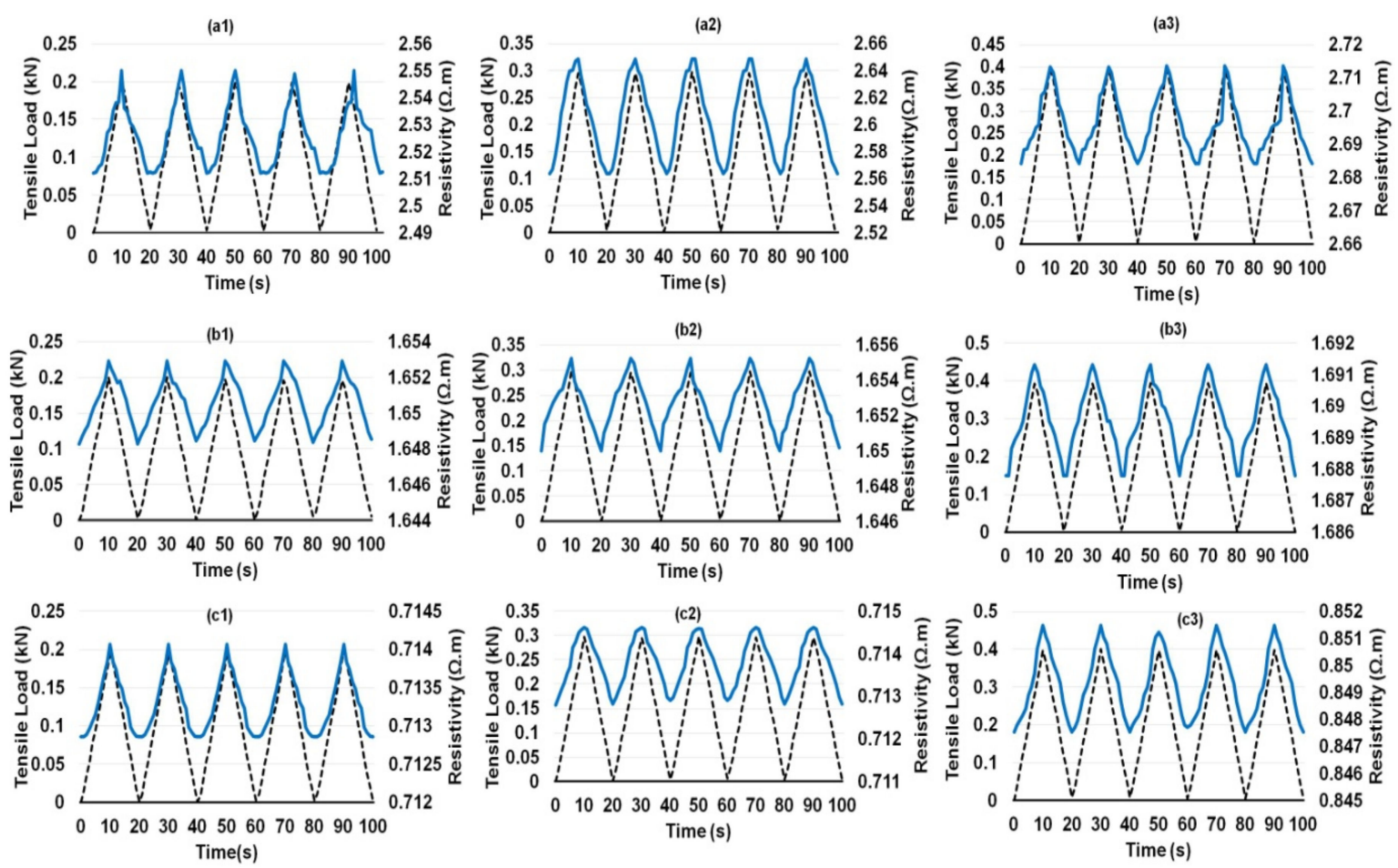

Figure 13. Change of electrical resistance with cyclic tensile load of $0.15 \%$ MWCNT-reinforced cementitious composites at different peak loads containing $0.25 \%$ CF (a1-a3), 0.50\%SCF (b1-b3) and $0.75 \%$ SCF (c1-c3).

\subsubsection{Fractional Change in Electrical Resistivity and Stress Sensitivity}

The average FCR values of five loading cycles for different composites and at different loading conditions are listed in Tables 4 and 5. It is clear from Table 4 that the average FCR values of CF-reinforced cementitious composites were dependent on the loading rate (and maximum load) and on the amount of CF in these composites.

Table 4. Fractional resistance change of composites containing CF.

\begin{tabular}{|c|c|c|}
\hline Samples & Loading Rate (N.s $\left.{ }^{-1}\right)$, Max Load (N) & FCR \\
\hline \multirow{3}{*}{ Mortar with $0.25 \%$ CF } & 20,200 & 0.177 \\
\hline & 30,300 & 0.165 \\
\hline & 40,400 & 0.148 \\
\hline \multirow{3}{*}{ Mortar with $0.5 \% \mathrm{CF}$} & 20,200 & 0.042 \\
\hline & 30,300 & 0.082 \\
\hline & 40,400 & 0.231 \\
\hline \multirow{3}{*}{ Mortar with $0.75 \%$ CF } & 20,200 & 0.074 \\
\hline & 30,300 & 0.045 \\
\hline & 40,400 & 0.097 \\
\hline
\end{tabular}


Table 5. Fractional resistance change of composites containing CF along with CNF/MWCNT.

\begin{tabular}{|c|c|c|c|}
\hline \multirow{2}{*}{ Samples } & \multirow{2}{*}{ Loading Rate (N.s $\left.{ }^{-1}\right)$, Max. Load (N) } & \multicolumn{2}{|c|}{ FCR } \\
\hline & & CNF & MWCNT \\
\hline \multirow{3}{*}{$\begin{array}{l}\text { Mortar }+0.25 \% \mathrm{CF}+ \\
0.1 \% \mathrm{CNF} / \mathrm{MWCNT}\end{array}$} & $20,200 \mathrm{~N}$ & 0.003 & 0.030 \\
\hline & $30,300 \mathrm{~N}$ & 0.004 & 0.029 \\
\hline & $40,400 \mathrm{~N}$ & 0.017 & 0.029 \\
\hline \multirow{3}{*}{$\begin{array}{c}\text { Mortar+ 0.25\% CF + } \\
0.15 \% \text { CNF/MWCNT }\end{array}$} & $20,200 \mathrm{~N}$ & 0.004 & 0.015 \\
\hline & $30,300 \mathrm{~N}$ & 0.009 & 0.033 \\
\hline & $40,400 \mathrm{~N}$ & 0.015 & 0.011 \\
\hline \multirow{3}{*}{$\begin{array}{c}\text { Mortar }+0.5 \% \text { CF }+ \\
0.1 \% \text { CNF } / \text { MWCNT }\end{array}$} & $20,200 \mathrm{~N}$ & 0.010 & 0.039 \\
\hline & $30,300 \mathrm{~N}$ & 0.008 & 0.038 \\
\hline & $40,400 \mathrm{~N}$ & 0.008 & 0.028 \\
\hline \multirow{3}{*}{$\begin{array}{c}\text { Mortar }+0.5 \% \text { CF + } \\
0.15 \% \text { CNF/MWCNT }\end{array}$} & $20,200 \mathrm{~N}$ & 0.005 & 0.003 \\
\hline & $30,300 \mathrm{~N}$ & 0.010 & 0.003 \\
\hline & $40,400 \mathrm{~N}$ & 0.017 & 0.002 \\
\hline \multirow{3}{*}{$\begin{array}{l}\text { Mortar + 0.75\%CF + } \\
0.1 \% \text { CNF } / \mathrm{MWCNT}\end{array}$} & $20,200 \mathrm{~N}$ & 0.013 & 0.008 \\
\hline & $30,300 \mathrm{~N}$ & 0.010 & 0.007 \\
\hline & $40,400 \mathrm{~N}$ & 0.008 & 0.006 \\
\hline \multirow{3}{*}{$\begin{array}{c}\text { Mortar }+0.75 \% \mathrm{CF}+ \\
0.15 \% \text { CNF } / \mathrm{MWCNT}\end{array}$} & $20,200 \mathrm{~N}$ & 0.021 & 0.002 \\
\hline & $30,300 \mathrm{~N}$ & 0.028 & 0.002 \\
\hline & $40,400 \mathrm{~N}$ & 0.037 & 0.005 \\
\hline
\end{tabular}

The influence of the loading rate and maximum load on FCR, however, did not show any clear trend. Previous studies on hybrid nano-carbon containing piezoresistivity cementitious composites showed a decrease in FCR with the increasing rate of compressing loading [13]. This was attributed to the reduced compressive strains with the increasing loading rates, resulting in the reduced resistivity change in each cycle. However, the effect of loading rates on the resistivity change of short CF-based cement composites has not been reported to date. In the present study, both the loading rate and maximum load were changed simultaneously, and this made it difficult to understand their individual effects. An increase in FCR with the increase in the maximum tensile strain per cycle in the elastic regime was previously observed in short CF-based piezoresistive composites [4,5]. In the present case, the increase in loading rates (from 20 to $40 \mathrm{~N} / \mathrm{s}$ ) could decrease the tensile strain of composites, as observed previously in cement-based composites [26]. However, the increase in the maximum load (from 200 to $400 \mathrm{~N}$ ) could also increase the tensile strain at the same time and, therefore, no clear trend was observed due to these two opposing effects. Further studies by changing the loading rates while maintaining the same maximum load could help to properly understand this phenomenon.

It can also be observed from Table 4 that the FCR values were higher in the case of composites containing $0.25 \% \mathrm{CFs}$ when compared to composites with 0.5 and $0.75 \% \mathrm{CFs}$. $\mathrm{CFs}$ formed an electrical percolation network at $0.25 \%$ as evidenced by the low resistivity values (see Figure 8). Similar resistivity values were reported previously for CF-based and other cementitious composites above the percolation threshold of the conductive fillers [21-24]. Therefore, the composites containing $0.25 \% \mathrm{CFs}$ provided high values of FCR. Previously reported CF-based composites also showed similar FCR values under tensile loading $[4,5]$. The decrease in FCR at higher CF contents could be attributed to the fact the higher amount of CFs resulted in more touching of CFs and a high number of conductive pathways. This resulted in lower change in the conducting network under tensile deformation and consequently, a lower change in the electrical resistance. This 
phenomenon was previously observed in the case of CF-reinforced piezoresistive polymeric composites $[27,28]$.

It is clear from Table 5 that the cementitious composites with hybrid fillers, i.e., CFs along with CNFs/CNTs showed lower FCR values when compared to only CF-based composites. The reason for this is the same as discussed above for 0.5 and $0.75 \%$ CF-based cementitious composites. The presence of CNF and MWCNTs significantly increased the number of conductive pathways and more touching between the conductive fillers, making the conductive network more stable and less sensitive to the mechanical deformations. Figure 14 explains this phenomenon schematically. It can be observed that when the CF content is low (Figure 14a), the conductive network becomes extended under tensile deformation, increasing the distance between CFs (indicated by dotted circles) and leading to a significant increase in the electrical resistivity. However, at higher $\mathrm{CF}$ contents, e.g., $0.75 \%$ (Figure 14b), due to higher number of electrical contacts the extension of the conductive network does not significantly change the electrical contact points and, therefore, the change in electrical resistivity is limited. Similarly, the presence of MWCNTs/CNFs in the case of $0.25 \%$ CF (Figure 14c) can maintain the electrical contacts between CFs when the conductive network extends under tensile deformation (as can be seen in the dotted circles in Figure 14c). Therefore, the presence of MWCNTs/CNFs results in a significantly lower change in the electrical resistivity under tensile loading. Observations made by Kim et al. support this hypothesis as it was noticed that the hybrid fillers composed of CFs and CNTs made the electrically resistivity less sensitive to the change in water to cement ratio, temperature and evaporation of electrolytic pore solution, due to the extended conductive pathways [14]. However, the authors did not evaluate the effect of hybrid fillers on the piezoresistive properties of the composites.

(a)

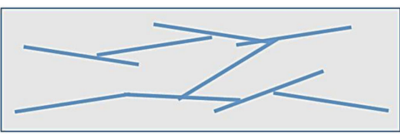

(b)
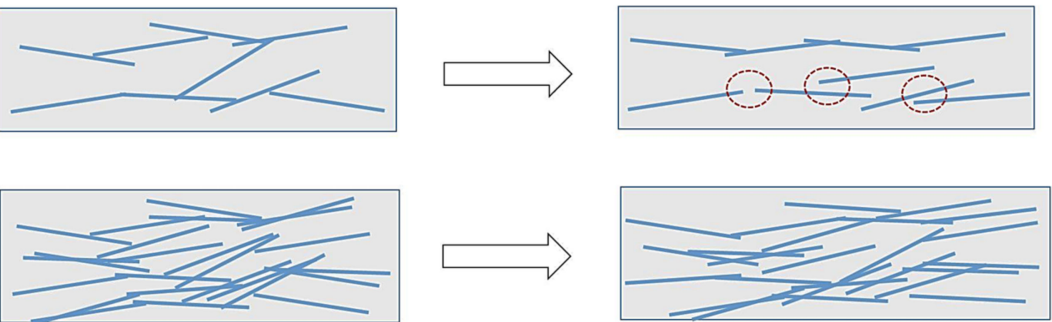

(c)

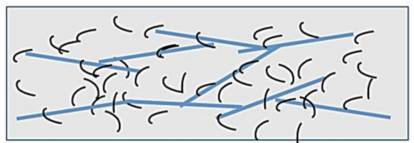

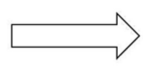

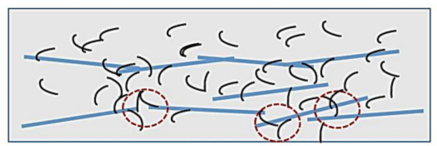

Figure 14. Change in the electorally conductive network under tensile deformation of (a) $0.25 \% \mathrm{CF}$, (b) $0.75 \% \mathrm{CF}$ and (c) $0.25 \% \mathrm{CF}$ with CNFs / MWCNTs.

FCR values of cementitious composites containing different concentrations of hybrid fillers are compared in Table 5 . It can be noticed that the hybrid composites showed different FCR values depending on the CF, CNF and MWCNT concentrations, as well as the loading conditions, i.e., the rate and maximum load. Similar to CF-based composites, the influence of loading conditions on FCR values did not show any clear trend. The FCR values have been further converted into stress sensitivity according to Equation (2) and are presented in Figure 15. Stress sensitivity is a better parameter to compare the load/stress sensing behavior of cementitious composites containing different concentrations of conductive fillers. It can be observed that the CF-based composites showed a considerably higher stress sensitivity when compared to the hybrid composites due to the higher FCR values of the former, as explained earlier. 


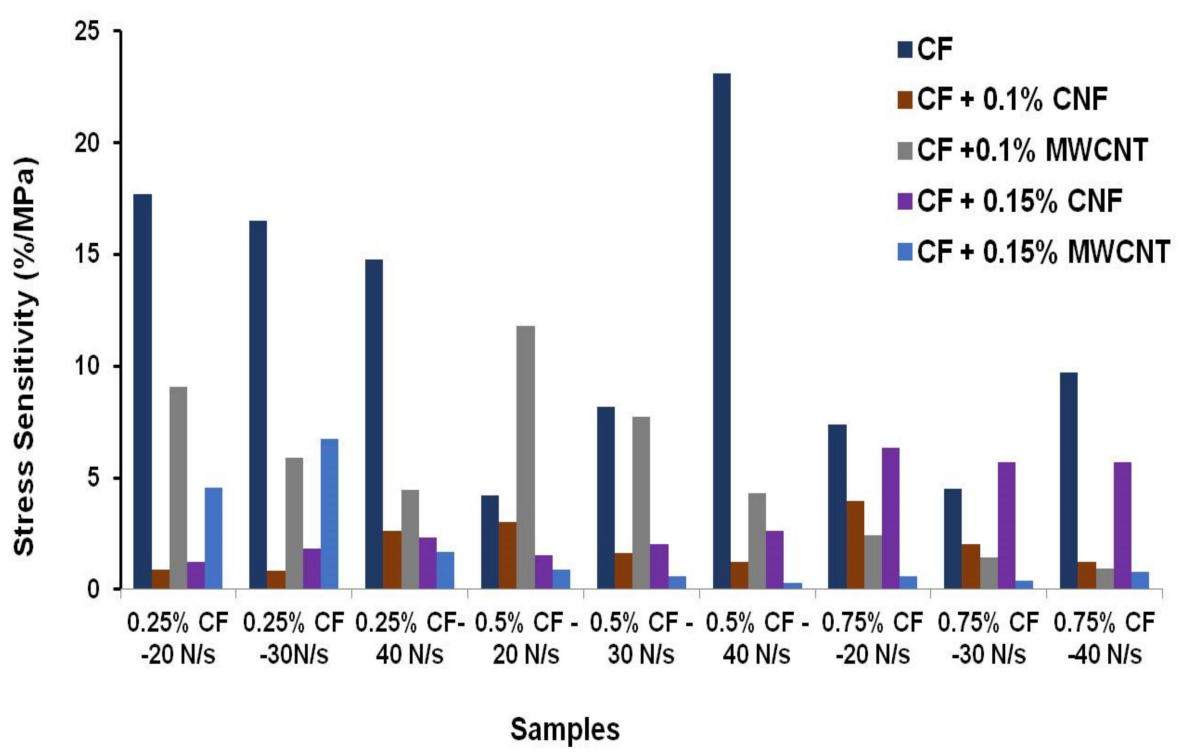

Figure 15. Stress sensitivity of various cement based sensors.

In the cases of hybrid composites with 0.25 and $0.5 \% \mathrm{CF}$, the use of MWCNTs led to superior stress sensitivity when compared to CNFs. On the contrary, the stress sensitivity was higher with $\mathrm{CNFs}$ when compared to MWCNTs when a higher amount of $\mathrm{CF}$, i.e., $0.75 \mathrm{wt.} \% \mathrm{CF}$ was used in the composites. The superior sensitivity of MWCNT-based composites at lower CF contents could be attributed to the superior ability of MWCNTs to form a piezoresistive network due to their higher electrical conductivity and smaller dimensions. At higher CF contents, a saturation in the electrically conducting pathways resulted in a lower sensitivity of these composites. Also, the stress sensitivity was superior with $0.1 \%$ MWCNTs when compared to $0.15 \%$ and this could be due to the increased agglomeration of MWCNTs at $0.15 \%$ when dispersed using the same process. On the contrary, composites with $0.15 \%$ CNF showed superior stress sensitivity when compared to those with $0.1 \%$ CNF. This could be attributed to the fact that CNFs could be more homogeneously dispersed at higher concentrations when compared to MWCNTs using the same dispersion process, due to their lower surface area and agglomeration tendency [29].

The highest stress sensitivities achieved with hybrid composites containing $0.15 \%$ CNFs and $0.1 \%$ CNTs were 6.36 and $11.82 \% / \mathrm{MPa}$ at 0.75 and $0.5 \% \mathrm{CF}$ contents, respectively. The observed stress sensitivity values were much higher when compared to those previously reported for hybrid nano-carbon-reinforced cementitious composites under compression loading [13].

\subsection{FCR-Load Correlations of Developed Sensing Composites}

The relationships between FCR and load for cementitious composites containing different CF contents at different loading conditions are shown in Figure 16. It can be observed that the change in FCR with the tensile load was dependent on the loading conditions. From the values of linear regression coefficients $\left(R^{2}\right)$, it can be commented that the cementitious composites containing only CFs did not show a good linear correlation between FCR and load (and stress, as stress is proportional to the applied load), making the calibration of these sensors difficult and leading to measurements with high error values. The large scatter of the FCR values indicates an uneven and random change in the electrical resistivity of the samples in different loading and unloading cycles. In CFbased cementitious composites, the loading and unloading cycles caused random and large changes in the electrical contact points between the CFs (schematically shown in Figure 14), making electrical resistivity change and FCR not linearly dependent on the applied load or stress. Further, presence of $\mathrm{CF}$ clusters could also lead to unpredictable and random change in the electrical network and, consequently, in the electrical resistivity of the composites. As 
a result, the scatter in the FCR data was high. As a reliable and accurate measurement with a low scattering of FCR values is required for practical applications, these CF-based sensors are not, therefore, suitable for sensing of tensile stresses in civil engineering structures. A high scatter of FCR values in the case of CF-based cementitious composites was previously observed in the case of compressive loading [15].
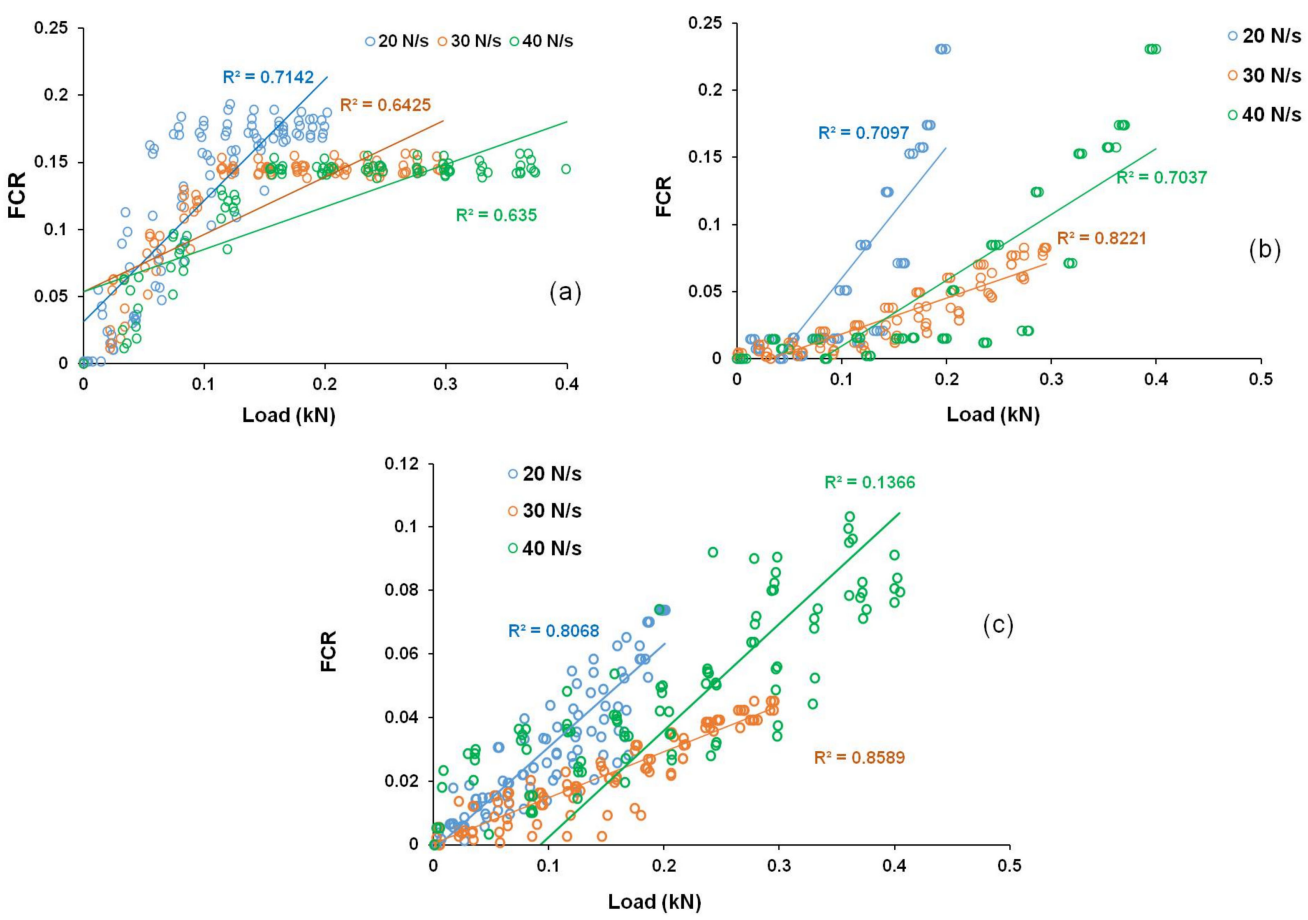

Figure 16. FCR-load correlation of cementitious composites containing different carbon fiber contents: (a) 0.25 wt. $\%$, (b) 0.5 wt. $\%$ and (c) 0.75 wt. $\%$.

The correlation between FCR and tensile load for CNF-based hybrid cementitious composites are shown in Figure 17. It can be observed that hybrid composites containing CNFs presented superior linear correlation between FCR and tensile load (and therefore, with tensile stress) and a lower scatter in FCR values when compared to the composites containing only CFs. It can also be noticed that among different samples, the sample containing $0.15 \%$ CNF with $0.75 \%$ CFs showed a good linear correlation with a low scatter of data. This composite also presented the best stress sensitivity $(6.36 \% / \mathrm{MPa})$ and therefore, can be considered as the optimized sample for developing CNF-based hybrid stress sensors for construction applications.

Figure 18 shows the FCR-load correlation for hybrid cementitious composites containing MWCNTs. It is clear that the correlation was much better with a lower scatter of data for these composites when compared to only CF-based and CNF-based hybrid cementitious composites. It can also be observed that the composites with $0.1 \% \mathrm{MWCNT}$ and $0.5 \% \mathrm{CF}$ showed a good linear correlation along with high stress sensitivity $(11.82 \% / \mathrm{MPa})$, as observed in Figure 15 and therefore, these composites can be considered as the best CNT-based hybrid cementitious sensors for the sensing of stresses in civil engineering structures. 

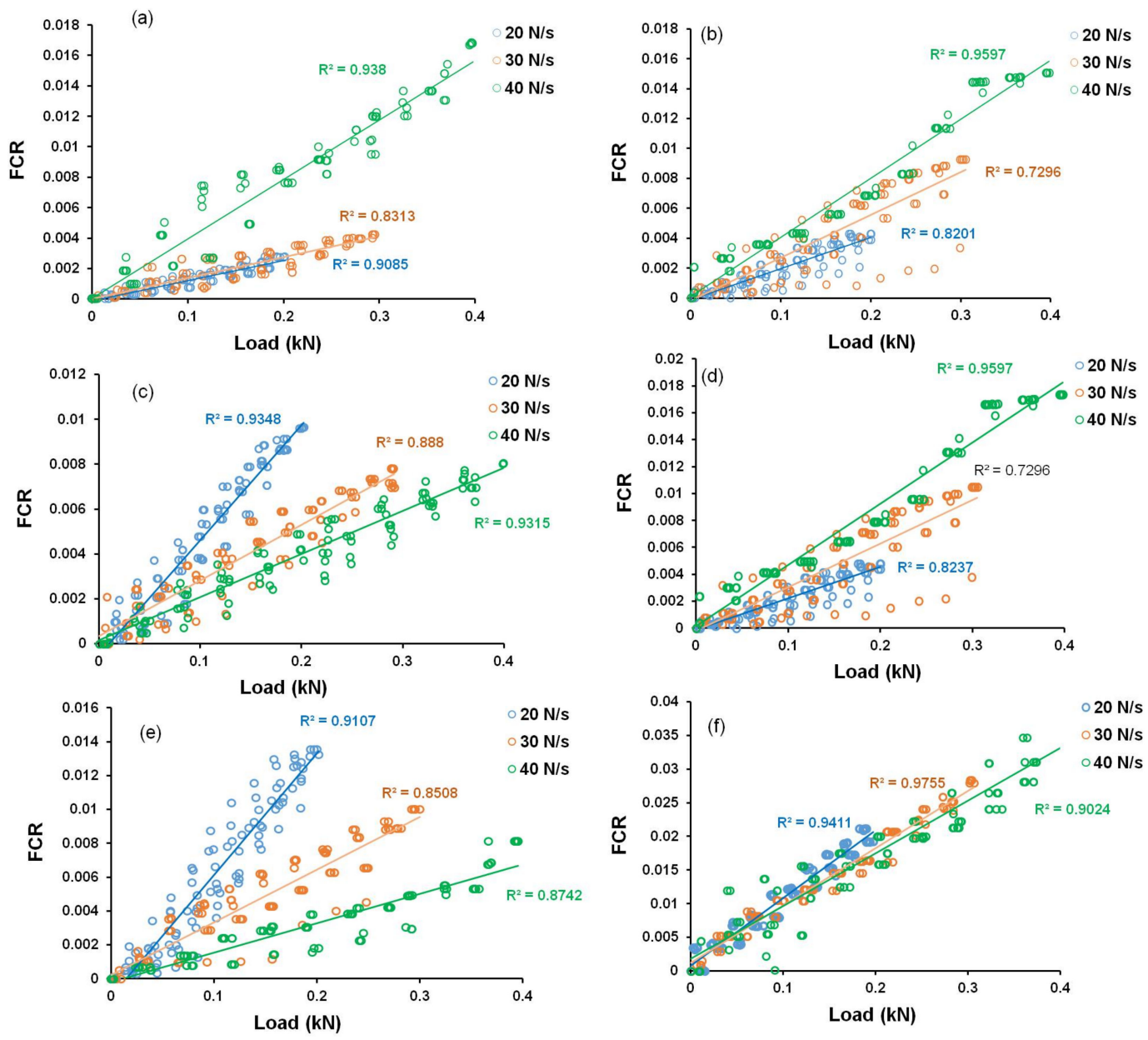

Figure 17. FCR-load correlation of CNF-based hybrid cementitious composites: (a) $0.25 \% \mathrm{CF}+0.1 \% \mathrm{CNF}$, (b) $0.25 \% \mathrm{CF}+0.15 \% \mathrm{CNF}$, (c) $0.5 \% \mathrm{CF}+0.1 \% \mathrm{CNF}$, (d) $0.5 \% \mathrm{CF}+0.15 \% \mathrm{CNF}$ (e) $0.75 \% \mathrm{CF}+0.1 \% \mathrm{CNF}$ and (f) $0.75 \% \mathrm{CF}+0.15 \% \mathrm{CNF}$.

As discussed earlier, the presence of CNFs and MWCNTs in CF-based cementitious composites increased the conductive pathways preventing random and abrupt changes in the electrical network under tensile loading. Therefore, a more stable, accurate and reliable piezoresistive behavior was obtained in the presence of MWCNTs/CNFs. The results were superior with MWCNTs at low concentrations when compared to CNFs, due to the higher electrical conductivity of MWCNTs and owing to their superior ability to form percolating and piezoresistive electrical networks when dispersed homogeneously, due to their smaller dimensions. It can be noticed in Figures 17 and 18 that the slopes of the FCR-load curves changed with the loading rates, indicating that the stress sensitivity was dependent on the loading rates. As discussed in Section 3.4.2, the loading rate could influence the tensile strain of the developed cementitious composites and this, in turn, influenced the change in the electrical resistivity. A higher loading rate was expected to reduce the tensile strain, thereby reducing the change in the electrical resistivity and stress sensitivity of the composites. However, in the present study, the applied load was also changed along with the loading rates, and this resulted in an opposite effect on stress sensitivity, i.e., an increase in the load could increase the tensile strain and increase the stress sensitivity. Due to this reason, the effect of the loading rate on the stress sensitivity of the developed composites was not very clear in the present study and needs to be further investigated. 

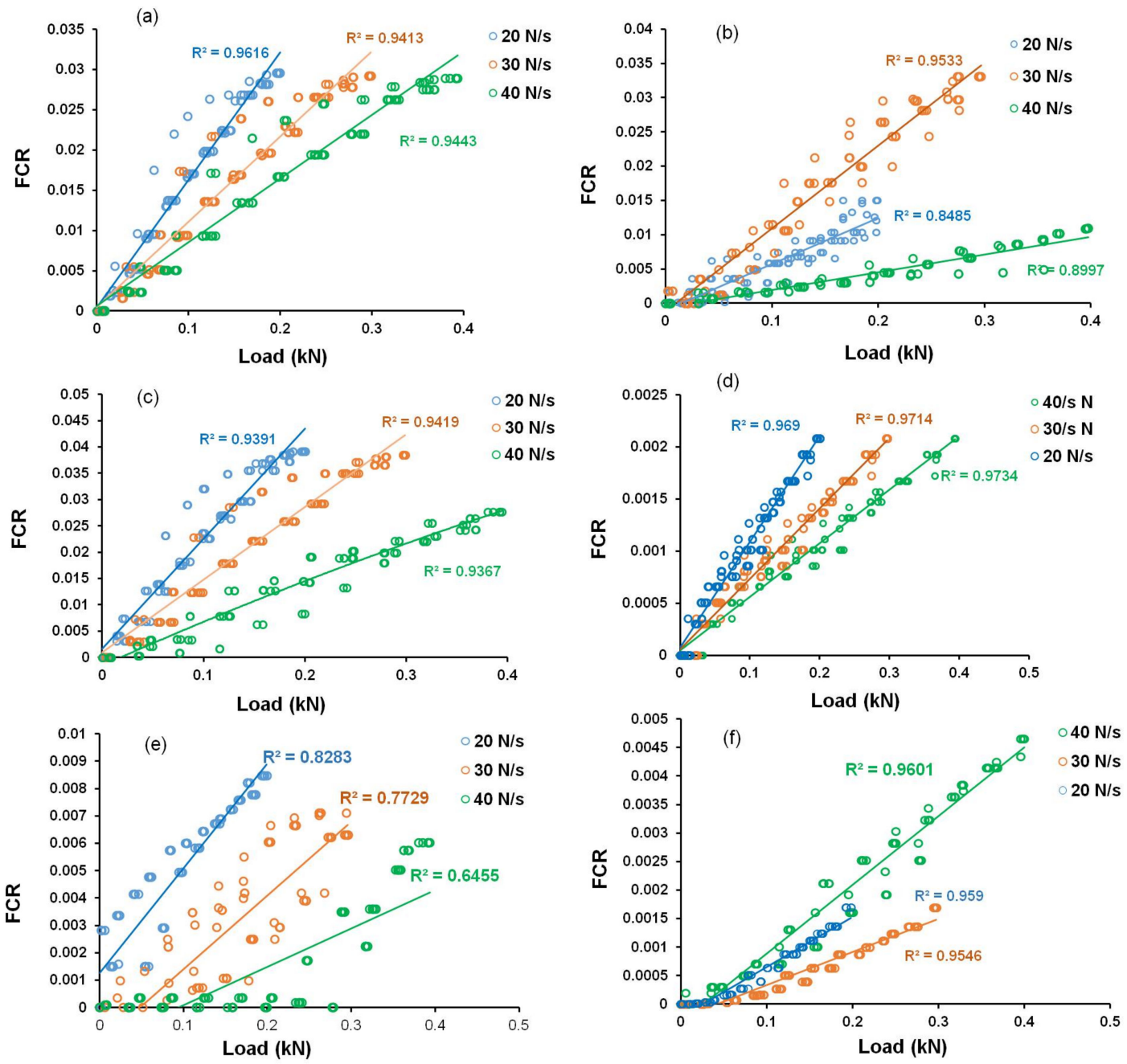

Figure 18. FCR-load correlation of MWCNT-based hybrid cementitious composites: (a) $0.25 \%$ CF $+0.1 \%$ MWCNT, (b) $0.25 \%$ CF $+0.15 \%$ MWCNT, (c) $0.5 \%$ CF $+0.1 \%$ MWCNT, (d) $0.5 \%$ CF $+0.15 \%$ MWCNT, (e) $0.75 \%$ CF $+0.1 \%$ MWCNT and (f) $0.75 \%$ CF $+0.15 \%$ MWCNT.

\subsection{Microstructure of Developed Cementitious Composites}

The fracture surfaces of broken samples in tensile tests (up to failure) were studied using SEM and are shown in Figure 19. It can be clearly observed from Figure 19a,b that $\mathrm{CFs}$ (indicated by arrows) were uniformly dispersed within cementitious composites. This confirmed that the used dispersion process using magnetic stirring along with Pluronic F-127 surfactant was able to ensure the homogeneous dispersion of CFs. CNFs and MWCNTs can also be observed in the fracture surface of hybrid composites, as can be seen in Figure 19c-f. It is interesting to note from Figure 19d-f that both CNFs and MWCNTs formed electrical connections between CFs and cement hydration products and helped to form the percolating and piezoresistive networks, as discussed earlier. The SEM micrographs of fracture surfaces support the mechanism of piezoresistivity, as illustrated in Figure 14. 


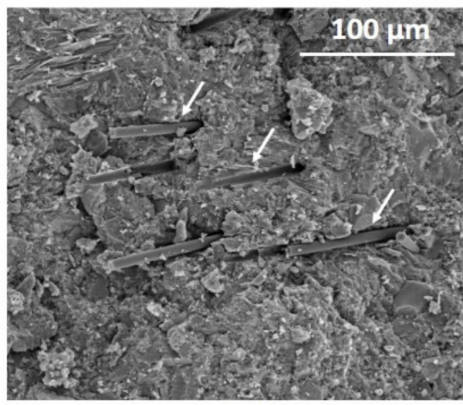

(a)

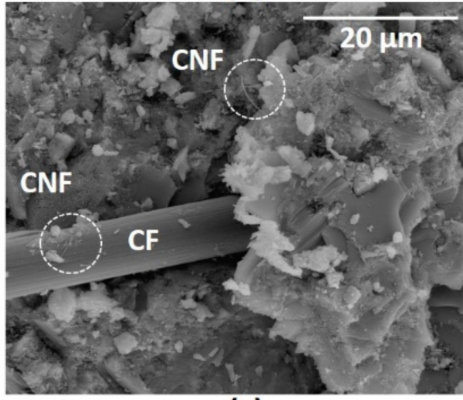

(c)

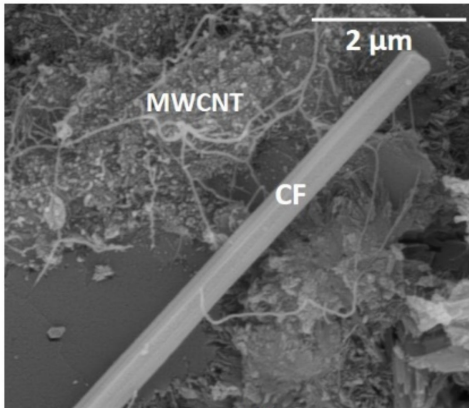

(e)

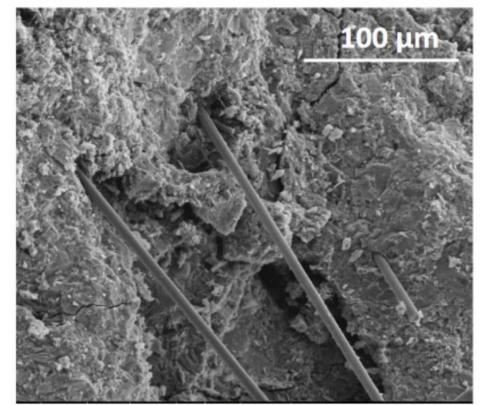

(b)

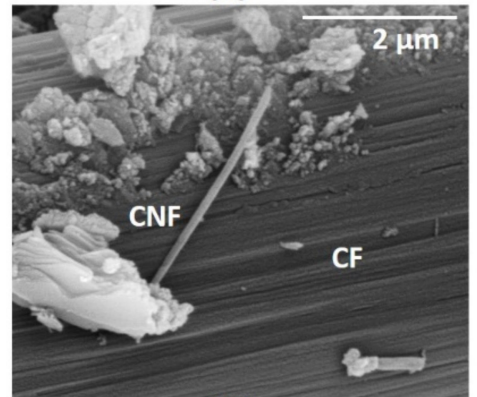

(d)

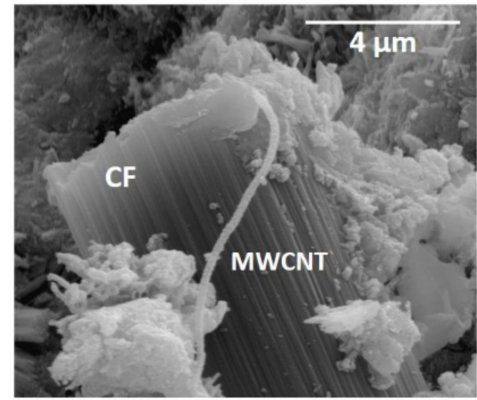

(f)

Figure 19. Fracture surface of a plain mortar $(\mathbf{a}, \mathbf{b})$, cementitious composite with CNFs $(\mathbf{c}, \mathbf{d})$ and a cementitious composite with MWCNTs (e,f) at different magnifications.

\section{Conclusions}

In this research, multi-scale cementitious composites were developed using CFs along with CNFs or MWCNTs and their stress-sensing behavior was characterized and compared with CF-based cementitious composites. The following conclusions can be made from the present study:

(1) The electrical resistivity of CF-based composites decreased with the increase in CF content from 0.25 to $0.75 \%$. The incorporation of CNF and MWCNT $(0.1$ and $0.15 \%$ of cement weight) in CF-based composites led to a significant decrease in the electrical resistivity of cementitious composites.

(2) CF-based cementitious composites showed a reversible increase in electrical resistivity with the cyclic tensile load. The highest value of FCR was achieved at the lower CF content, i.e., $0.25 \%$ and an increase in the CF content resulted in a decrease in FCR due to the saturation in the electrical contact points reducing the stress sensitivity of the composites.

(3) Multi-scale cementitious composites also showed a reversible increase in the electrical resistivity with tensile loads. Overall, the multi-scale composites showed a lower FCR when compared to CF-based composites, due to an increase in the electrically conducting pathways. MWCNTs and CNFs formed connections between well-dispersed CFs and cement hydration products, forming a well-connected percolation network. 
(4) Although CF-based composites presented good stress sensitivity, the FCR-load correlation was not good and a high scatter in FCR values was noticed. This makes the CF-based cement sensors not suitable for accurately measuring tensile stresses in practical applications. On the contrary, the multi-scale composite sensors showed a good linear correlation between FCR and tensile loads with a low scatter of data. Superior results were obtained in the case of MWCNT-based multi-scale composites when compared to the CNF-based composites. The best CNF- and MWCNT-based sensors provided stress sensitivity of 6.36 and $11.82 \% / \mathrm{MPa}$, respectively.

Author Contributions: S.P.: involved in conceptualization, investigation, result analysis, writingoriginal draft, project management. B.V.: investigation, result analysis, O.L.: investigation, result analysis, S.R.: involved in conceptualization, results analysis, review and editing, project management, funding acquisition. R.F.: involved in conceptualization, project administration, funding acquisition. All authors have read and agreed to the published version of the manuscript.

Funding: The research is funded by Fibrenamics, Institute of Innovation in Fiber-based Materials and Composites and University of Minho-Guimarães, Portugal, Project UID/CTM/00264/2019 of 2C2T-Centro de Ciência e Tecnologia Têxtil, funded by National Funds through FCT/MCTES. The APC is funded by the School of Arts and Humanities, University of Huddersfield and Fibernamics, Institute of Innovation in Fiber-based Materials and Composites and University of Minho-Guimarães, Portugal, Project UID/CTM/00264/2019 of 2C2T_Centro de Ciência e Tecnologia Têxtil, funded by National Funds through FCT/MCTES.

Data Availability Statement: The raw/processed data required to reproduce these findings cannot be shared at this time as the data also forms part of an ongoing study. The relevant data can be made available on request.

Conflicts of Interest: The authors declare no conflict of interest.

\section{References}

1. Brownjohn, J.M.W. Structural health monitoring of civil infrastructure. Philos. Trans. R. Soc. A Math. Phys. Eng. Sci. 2007, 365, 589-622. [CrossRef]

2. Rana, S.; Subramani, P.; Fangueiro, R.; Correia, A.G. A review on smart self-sensing composite materials for civil engineering applications. AIMS Mater. Sci. 2016, 3, 357-379. [CrossRef]

3. Dong, W.; Li, W.; Tao, Z.; Wang, K. Piezoresistive properties of cement-based sensors: Review and perspective. Constr. Build. Mater. 2019, 203, 146-163. [CrossRef]

4. Wen, S.; Chung, D.D.L. Uniaxial tension in carbon fiber reinforced cement, sensed by electrical resistivity measurement in longitudinal and transverse directions. Cem. Concr. Res. 2000, 30, 1289-1294. [CrossRef]

5. Chung, D.D.L. Piezoresistive cement-based materials for strain sensing. J. Intell. Mater. Syst. Struct. 2002, 13, 599-609. [CrossRef]

6. Dong, W.; Li, W.; Wang, K.; Guo, Y.; Sheng, D.; Shah, S.P. Piezoresistivity enhancement of functional carbon black filled cement-based sensor using polypropylene fibre. Powder Technol. 2020, 373, 184-194. [CrossRef]

7. D'Alessandro, A.; Rallini, M.; Ubertini, F.; Materazzi, A.L.; Kenny, J.M. Investigations on scalable fabrication procedures for self-sensing carbon nanotube cement-matrix composites for SHM applications. Cem. Concr. Compos. 2016, 65, 200-213. [CrossRef]

8. Yoo, D.Y.; You, I.; Lee, S.J. Electrical and piezoresistive sensing capacities of cement paste with multi-walled carbon nanotubes. Arch. Civ. Mech. Eng. 2018, 18, 371-384. [CrossRef]

9. Parveen, S.; Rana, S.; Fangueiro, R. A Review on Nanomaterial Dispersion, Microstructure, and Mechanical Properties of Carbon Nanotube and Nanofiber Reinforced Cementitious Composites. J. Nanomater. 2013, 2013, 710175. [CrossRef]

10. Parveen, S.; Rana, S.; Fangueiro, R.; Paiva, M.C. Microstructure and mechanical properties of carbon nanotube reinforced cementitious composites developed using a novel dispersion technique. Cem. Concr. Res. 2015, 73, 215-227. [CrossRef]

11. Parveen, S.; Rana, S.; Fangueiro, R.; Paiva, M.C. Characterizing dispersion and long term stability of concentrated carbon nanotube aqueous suspensions for fabricating ductile cementitious composites. Powder Technol. 2017, 307, 15-24. [CrossRef]

12. Zheng, Q.; Han, B.; Cui, X.; Yu, X.; Ou, J. Graphene-engineered cementitious composites: Small makes a big impact. Nanomater. Nanotechnol. 2017, 7, 1847980417742304. [CrossRef]

13. Han, B.; Wang, Y.; Ding, S.; Yu, X.; Zhang, L.; Li, Z.; Ou, J. Self-sensing cementitious composites incorporated with botryoid hybrid nano-carbon materials for smart infrastructures. J. Intell. Mater. Syst. Struct. 2017, 28, 699-727. [CrossRef]

14. Kim, G.; Park, S.; Ryu, G.; Lee, H.-K. Electrical characteristics of hierarchical conductive pathways in cementitious composites incorporating CNT and carbon fiber. Cem. Concr. Compos. 2017, 82, 65-75. [CrossRef]

15. Azhari, F.; Banthia, N. Cement-based sensors with carbon fibers and carbon nanotubes for piezoresistive sensing. Cem. Concr. Compos. 2012, 34, 866-873. [CrossRef] 
16. Zhang, L.; Ding, S.; Li, L.; Dong, S.; Wang, D.; Yu, X.; Han, B. Effect of characteristics of assembly unit of CNT/NCB composite fillers on properties of smart cement-based materials. Compos. Part A Appl. Sci. Manuf. 2018, 109, 303-320. [CrossRef]

17. Hunashyal, A.M.; Quadri, S.S.; Banapurmath, N.R. Experimental investigation on the study of mechanical and microstructural properties of hybrid composite cement beams reinforced with multi-walled carbon nanotubes and carbon fibres. Proc. Inst. Mech. Eng. Part N J. Nanoeng. Nanosyst. 2012, 226, 135-142. [CrossRef]

18. Hunashyal, A.M.; Tippa, S.V.; Quadri, S.S.; Banapurmath, N.R. Experimental investigation on effect of carbon nanotubes and carbon fibres on the behavior of plain cement mortar composite round bars under direct tension. Int. Sch. Res. Not. 2011, 2011, 856849. [CrossRef]

19. Al-Saleh, M.H.; Sundararaj, U. A review of vapor grown carbon nanofiber/polymer conductive composites. Carbon 2009, 47, 2-22. [CrossRef]

20. Tessonnier, J.P.; Rosenthal, D.; Hansen, T.W.; Hess, C.; Schuster, M.E.; Blume, R.; Girgsdies, F.; Pfänder, N.; Timpe, O.; Su, D.S.; et al. Analysis of the structure and chemical properties of some commercial carbon nanostructures. Carbon 2009, 47, 1779-1798. [CrossRef]

21. Ozbulut, O.E.; Jiang, Z.; Harris, D.K. Exploring scalable fabrication of self-sensing cementitious composites with graphene nanoplatelets. Smart Mater. Struct. 2018, 27, 115029. [CrossRef]

22. Monteiro, A.O.; Cachim, P.B.; Costa, P.M.F.J. Self-sensing piezoresistive cement composite loaded with carbon black particles. Cem. Concr. Compos. 2017, 81, 59-65. [CrossRef]

23. Liu, C.; Liu, G.; Ge, Z.; Guan, Y.; Cui, Z.; Zhou, J. Mechanical and Self-Sensing Properties of Multiwalled Carbon NanotubeReinforced ECCs. Adv. Mater. Sci. Eng. 2019, 2019, 2646012. [CrossRef]

24. Donnini, J.; Bellezze, T.; Corinaldesi, V. Mechanical, electrical and self-sensing properties of cementitious mortars containing short carbon fibers. J. Build. Eng. 2018, 20, 8-14. [CrossRef]

25. Kim, G.M.; Yang, B.J.; Cho, K.J.; Kim, E.M.; Lee, H.K. Influences of CNT dispersion and pore characteristics on the electrical performance of cementitious composites. Compos. Struct. 2017, 164, 32-42. [CrossRef]

26. Yang, E.H.; Li, V.C. Strain-rate effects on the tensile behavior of strain-hardening cementitious composites. Constr. Build. Mater. 2014, 52, 96-104. [CrossRef]

27. Bakis, C.E.; Nanni, A.; Terosky, J.A.; Koehler, S.W. Self-monitoring, pseudo-ductile, hybrid FRP reinforcement rods for concrete applications. Compos. Sci. Technol. 2001, 61, 815-823. [CrossRef]

28. Rana, S.; Zdraveva, E.; Pereira, C.; Fangueiro, R.; Correia, A.G. Development of hybrid braided composite rods for reinforcement and health monitoring of structures. Sci. World J. 2014, 2014, 170187. [CrossRef]

29. Rana, S.; Alagirusamy, R.; Joshi, M. A review on carbon epoxy nanocomposites. J. Reinf. Plast. Compos. 2009, 28, 461-487. [CrossRef] 